\title{
On the characteristics of aerosol indirect effect based on dynamic regimes in global climate models
}

\author{
Shipeng Zhang ${ }^{1,2,3}$, Minghuai Wang ${ }^{1,2,3}$, Steven J. Ghan ${ }^{3}$, Aijun Ding ${ }^{1,2}$, Hailong Wang ${ }^{3}$, Kai Zhang ${ }^{3}$, \\ David Neubauer $^{4}$, Ulrike Lohmann ${ }^{4}$, Sylvaine Ferrachat ${ }^{4}$, Toshihiko Takeamura ${ }^{5}$, Andrew Gettelman ${ }^{6}$, \\ Hugh Morrison $^{6}$, Yunha Lee ${ }^{7}$, Drew T. Shindell ${ }^{7}$, Daniel G. Partridge ${ }^{8,9,10}$, Philip Stier ${ }^{8}$, Zak Kipling ${ }^{8}$, and \\ Congbin $\mathrm{Fu}^{1,2}$ \\ ${ }^{1}$ Institute for Climate and Global Change Research and School of Atmospheric Sciences, Nanjing University, Nanjing, China \\ ${ }^{2}$ Collaborative Innovation Center of Climate Change, Jiangsu Province, China \\ ${ }^{3}$ Atmospheric Science and Global Change Division, Pacific Northwest National Laboratory, Richland, Washington, USA \\ ${ }^{4}$ ETH Zurich, Institute for Atmospheric and Climate Science, Zurich, Switzerland \\ ${ }^{5}$ Research Institute for Applied Mechanic, Kyushu University, Fukuoka, Japan \\ ${ }^{6}$ National Center for Atmospheric Research, Boulder, Colorado, USA \\ ${ }^{7}$ Earth and Ocean Sciences, Nicholas School of the Environment, Duke University, Durham, North Carolina, USA \\ ${ }^{8}$ Atmospheric, Oceanic and Planetary Physics, Department of Physics, University of Oxford, Oxford, UK \\ ${ }^{9}$ Department of Environmental Science and Analytical Chemistry, Stockholm University, Stockholm, Sweden \\ ${ }^{10}$ Bert Bolin Centre for Climate Research, Stockholm University, Stockholm, Sweden
}

Correspondence to: Minghuai Wang (minghuai.wang@nju.edu.cn)

Received: 5 August 2015 - Published in Atmos. Chem. Phys. Discuss.: 2 September 2015

Revised: 30 January 2016 - Accepted: 21 February 2016 - Published: 4 March 2016

\begin{abstract}
Aerosol-cloud interactions continue to constitute a major source of uncertainty for the estimate of climate radiative forcing. The variation of aerosol indirect effects (AIE) in climate models is investigated across different dynamical regimes, determined by monthly mean $500 \mathrm{hPa}$ vertical pressure velocity $\left(\omega_{500}\right)$, lower-tropospheric stability (LTS) and large-scale surface precipitation rate derived from several global climate models (GCMs), with a focus on liquid water path (LWP) response to cloud condensation nuclei (CCN) concentrations. The LWP sensitivity to aerosol perturbation within dynamic regimes is found to exhibit a large spread among these GCMs. It is in regimes of strong largescale ascent $\left(\omega_{500}<-25 \mathrm{hPa} \mathrm{day}^{-1}\right)$ and low clouds (stratocumulus and trade wind cumulus) where the models differ most. Shortwave aerosol indirect forcing is also found to differ significantly among different regimes. Shortwave aerosol indirect forcing in ascending regimes is close to that in subsidence regimes, which indicates that regimes with strong large-scale ascent are as important as stratocumulus regimes in studying AIE. It is further shown that shortwave aerosol indirect forcing over regions with high monthly large-scale
\end{abstract}

surface precipitation rate $\left(>0.1 \mathrm{~mm} \mathrm{day}^{-1}\right)$ contributes the most to the total aerosol indirect forcing (from 64 to nearly $100 \%$ ). Results show that the uncertainty in AIE is even larger within specific dynamical regimes compared to the uncertainty in its global mean values, pointing to the need to reduce the uncertainty in AIE in different dynamical regimes.

\section{Introduction}

By scattering and absorbing sunlight, aerosol particles can modify the solar radiation reaching the earth system, which is termed the direct effect. The direct radiative effect of anthropogenic aerosols combined with subsequent rapid adjustments of the surface energy budget, atmospheric state variables, and cloudiness to aerosol radiative effects is referred to as Effective Radiative Forcing from aerosol-radiation interactions (ERFari) (Boucher et al., 2013). Apart from ERFari, aerosols can also alter the Earth's radiation balance via interactions with clouds, such as effects on cloud albedo and subsequent changes to the cloud lifetime and thermodynamics 
as rapid adjustments, known as the aerosol indirect effect(s) (AIE). These radiative effects are called Effective Radiative Forcing from aerosol-cloud interactions (ERFaci) (Boucher et al., 2013).

For liquid clouds, there are two principal ways through which aerosols interact with them in AIE. First, an increase in cloud condensation nuclei (CCN) concentration from anthropogenic aerosols leads to smaller cloud droplet sizes assuming constant liquid water content. The increased number but decreased droplet sizes in turn increase cloud albedo due to more efficient backscattering. This is called the cloud albedo effect or the first AIE, also known as the Twomey effect (Twomey, 1977). Moreover, the smaller cloud droplet sizes are hypothesized to lead to decreases in precipitation efficiency, which may further alter cloud liquid water path (LWP) and cloud lifetime (Albrecht, 1989). These adjustments are also referred to as the cloud lifetime effect or the second AIE. It is worth noting that delaying the onset of precipitation may further modify latent heating profiles, which could lead to the invigoration of convective clouds (e.g., Andreae et al., 2004; Rosenfeld et al., 2008). There are also adjustments on mixed-phase and ice clouds (e.g., Storelvmo et al., 2008; Lohmann and Hoose, 2009; Liu et al., 2012b; Wang et al., 2014). The focus of this study is on liquid cloud response to aerosol perturbation, primarily from large-scale clouds.

AIE could be large enough to offset much of the global warming induced by anthropogenic greenhouse gases, yet its magnitude is still very uncertain (IPCC, 2013). The uncertainty in the cloud lifetime effect of aerosols is particularly large.

The complexity of microphysical-dynamical-radiative feedbacks involved in the cloud lifetime effect has been noted in previous studies. Conventional theory regarding the cloud lifetime effect suggests that higher $\mathrm{CCN}$ concentration slows down precipitation formation and hence leads to more LWP (Albrecht, 1989). However, this theory is inconsistent with some observations (Coakley and Walsh, 2002; Kaufman et al., 2005; Matsui et al., 2006; Chen et al., 2014) and large eddy simulations (LESs) (e.g., Ackerman et al., 2004; Lu and Seinfeld, 2005; Wang and Feingold, 2009b) that found either an increase or decrease in LWP in responses to increases in $\mathrm{CCN}$ concentration.

Further modeling studies (e.g., Ackerman et al., 2004; Stevens and Feingold, 2009; Guo et al., 2011) suggest that cloud top entrainment plays a critical role as a dynamic feedback, to balance LWP and modify the lifetime of boundary layer clouds. Ackerman et al. (2004) found that an increase in droplet number concentration $\left(N_{\mathrm{d}}\right)$ reduces cloud water sedimentation while accelerating the cloud-top entrainment rate, which makes the humidity of air overlying the boundary layer, wet or dry, critically important in determining the response of LWP. When surface precipitation is weak $\left(<0.1 \mathrm{~mm} \mathrm{day}^{-1}\right)$ and the overlying air is dry, LWP decreases in response to increasing aerosol. They showed that the entrainment rate was reduced by decreasing available boundary-layer turbulence kinetic energy (TKE). However, Bretherton et al. (2007) found that TKE remained unchanged and changes in entrainment rate are mainly caused by reduced evaporative cooling from removing out liquid water. LES studies (e.g., Wang and Feingold, 2009a) with a large model domain that is able to resolve mesoscale circulations (on the order of ten kilometers) in marine stratocumulus showed that aerosols can shift cloud regimes through their impact on precipitation and associated dynamical feedbacks. This can represent a more significant impact on cloud radiative forcing than the conventional AIE.

Many state-of-the-art global climate models (GCMs) appear to overestimate AIE when compared with satellite observations (e.g., Quaas et al., 2009; Wang et al., 2012), despite some uncertainties in satellite-derived estimates (e.g., Penner et al., 2011; Gryspeerdt et al., 2014a, b). The multiscale interactions between clouds, aerosols, and large-scale dynamics (Stevens and Feingold, 2009; Wang et al., 2011; Ma et al., 2015) and complex microphysical processes (e.g., Bretherton et al., 2007; Gettelman et al., 2013) cause uncertainties in estimating AIE by GCMs. One possible source of overestimation of AIE is their inability to reproduce negative LWP responses to aerosol perturbations, which are found in some observations and LES studies, partly because they do not explicitly simulate the droplet size effect on the entrainment process and on sub-grid cloud organizations associated with changes in precipitation. Guo et al. (2011) found that this effect could be captured through applying a parameterization based on multi-variate probability density functions with dynamics (MVD PDFs) in single-column simulations. They found decreased LWP in response to increasing aerosols concentration and suggested that the implementation of MVD PDFs in GCMs may help lower the magnitude of the simulated AIE. A negative correlation between LWP and aerosol loading was further found for clouds with weak precipitation and dry air above the PBL in a subsequent global model study (Guo et al., 2015).

Another likely source for the overestimation of cloud lifetime effects in GCMs is the treatment of cloud microphysics (Penner et al., 2006; Posselt and Lohmann, 2009; Wang et al., 2012). In warm clouds, cloud microphysical processes are dominated by autoconversion and accretion in bulk microphysics schemes (Gettelman et al., 2013). Since autoconversion acts as a sink of LWP, it is crucial in the formation of precipitation, and thus plays an important role in determining the cloud lifetime effect. The autoconversion rate is directly dependent on droplet number concentration $\left(N_{\mathrm{d}}\right)$ while the accretion rate is only weakly dependent on $N_{\mathrm{d}}$ (Khairoutdinov and Kogan, 2000; Gettelman et al., 2013). Furthermore, the ratio of the autoconversion rate to the large-scale surface precipitation rate is found to be strongly correlated with the LWP response to anthropogenic aerosol perturbations (e.g., Wang et al., 2012). Posselt and Lohmann (2009) suggested this ratio is related to the rain scheme adopted 
in GCMs. They showed that the adoption of different rain schemes (prognostic vs. diagnostic) in a GCM leads to a different LWP response to aerosol perturbations. A prognostic rain scheme can shift the importance of (warm) rain production from autoconversion process to the accretion process and therefore reduces the AIE (Posselt and Lohmann, 2009; Gettelman et al., 2015). However, Hill et al. (2015) shows that adding prognostic rain scheme alone still cannot reduce the spread of susceptibility of precipitation among different cloud microphysics parameterizations and further shows that increasing the complexity of the rain representation to double-moment significantly reduces the spread of precipitation sensitivity and improves overall consistency between bulk and bin schemes.

Previous studies are mostly confined to global averages (e.g Quaas et al., 2009; Wang et al., 2012) or a specific dynamic environment (e.g., Bretherton et al., 2007; Guo et al., 2011). However, aerosols, clouds, precipitation distributions, and dynamical feedbacks are all related to the prevailing meteorological environment (Stevens and Feingold, 2009). Clouds are sensitive to changes in dynamical regimes, which can be defined by large-scale circulations, thermodynamic structure, and meteorological backgrounds (Bony et al., 2004). Gryspeerdt and Stier (2012) and Gryspeerdt et al. (2014c) used satellite data and found that the characteristics of aerosol cloud-albedo effect (droplet number sensitivity) vary with cloud regimes and pointed out the importance of regime-based studies of aerosol-cloud interactions.

In this study, we investigate how AIE in several GCMs varies under different dynamical regimes over global oceans $\left(60^{\circ} \mathrm{S}-60^{\circ} \mathrm{N}\right)$, with a focus on cloud lifetime effects of aerosols (2nd AIE). We note that the term "cloud lifetime effects" can be somehow misleading, since aerosol effects on cloud liquid water may have little to do with cloud lifetime per se (e.g., Small et al., 2009). Nevertheless, this term is still used in some occasions in this paper for convenience. The paper is organized as follows. Methods and models are described in Sect. 2, and results and discussions are presented in Sect. 3. The paper concludes with the summary in Sect. 4.

\section{Methodology and models}

The response of LWP to aerosol perturbations is defined as

$\lambda=\mathrm{d} \ln \mathrm{LWP} / \mathrm{d} \ln \mathrm{CCN}$.

As simulated LWP and CCN can be quite different among GCMs, the logarithmic form of LWP and $\mathrm{CCN}$ is adopted in the $\lambda$ formula. $\lambda$ is a metric to quantitatively measure cloud lifetime effect of aerosols in models. It is directly calculated as the relative change of monthly mean LWP from pre-industrial (PI) to present day (PD) divided by the relative change of $\mathrm{CCN}$. Here d $\ln L W P=\left(L W P_{P D}-L_{W P}\right) / L W P_{P I}$ and $\mathrm{d} \ln \mathrm{CCN}=\left(\mathrm{CCN}_{\mathrm{PD}}-\mathrm{CCN}_{\mathrm{PI}}\right) / \mathrm{CCN}_{\mathrm{PI}}$, where $\mathrm{LWP}_{\mathrm{PD}}$ and
LWP $_{P I}$ are LWP in PD and PI, respectively, while $\mathrm{CCN}_{\mathrm{PD}}$ and $\mathrm{CCN}_{\mathrm{PI}}$ are $\mathrm{CCN}$ in $\mathrm{PD}$ and PI, respectively. This parameter was used by Wang et al. (2012) to constrain the cloud lifetime effects of aerosols over global oceans using precipitation frequency susceptibility $\left(S_{\text {pop }}\right)$ derived from A-Train satellite observations. Lebo and Feingold (2014) examined the relationship between $\lambda$ and $S_{\text {pop }}$ to aerosol perturbations for stratocumulus and trade-wind cumulus simulated by LES and found that $\lambda$ may increase in marine stratocumulus while decrease in the case of trade-wind cumulus in response to increasing $S_{\text {pop }}$, suggesting a cloud regime dependence of this relationship. Note that $\lambda$ allows some feedbacks, for example cloud effects on $\mathrm{CCN}$.

Dynamical regimes can be defined by environment characteristics such as large-scale vertical pressure velocity (e.g., Bony and Dufresne, 2005) and lower-tropospheric stability (LTS, defined as the difference in potential temperature between $700 \mathrm{hPa}$ and the surface, $\theta_{700 \mathrm{hPa}}-\theta_{\text {surface }}$ ) (e.g., Medeiros and Stevens, 2011). Medeiros and Stevens (2011) noted that low clouds and deep convective clouds could be separated by $\omega_{500}$ while different low cloud types under large-scale subsidence can only be depicted by using LTS. In this study the monthly averaged vertical pressure velocity $(\omega)$ in the mid-troposphere (defined as at $500 \mathrm{hPa}$ ) is used as a proxy for large-scale motions (Bony and Dufresne, 2005). Note that $\omega_{500}$ with positive (negative) value means descending (ascending) motions. We decompose global $\left(60^{\circ} \mathrm{S}-\right.$ $60^{\circ} \mathrm{N}$ ) large-scale circulations over ocean as a group of dynamical regimes (equally sampled) by $\omega_{500}$ (and LTS). Ascending regimes and descending regimes are defined by $\omega_{500}$ and descending regimes are further divided into stratocumulus, transitional clouds and trade wind cumulus regimes by LTS. This method is straight-forward to apply to GCM results and gives us a direct view of the relationship between clouds and their favorable large-scale environmental characteristics. Note however that the use of monthly means may obscure some details in the microphysical relationships, especially where the variability of cloud properties is high.

Since vertical pressure velocity is used as a major criterion here, dynamic regimes generally follow the features of vertical pressure velocity distributions. Descending regimes are mostly located at subtropical regions and western coasts of continents, while ascending regimes locates around the Inter-tropical Convergence Zone (ITCZ) and northern Pacific where storm tracks prevail. The seasonal evolution of dynamic regimes follows seasonal changes in the major meteorological systems. For example, ascending regimes move north and/or south as ITCZ move north and/or south and descending regimes move accompanying with subtropical high move. The characteristics of dynamic and thermodynamic regimes were discussed in detail in Bony et al. (2004).

As the perturbations in cloud radiative forcing from anthropogenic aerosols (indirect effect) are typically on the order of $1 \mathrm{~W} \mathrm{~m}^{-2}$, which is small compared to the cloud radiative forcing (shortwave radiative effect of $\sim-47 \mathrm{~W} \mathrm{~m}^{-2}$ 
Table 1. The types of clouds included in liquid water path (LWP) and surface rain rate and different rain schemes in 10 participating models

\begin{tabular}{lllc}
\hline Model & LWP & Rain & Rain scheme \\
\hline CAM5 & $\mathrm{S}^{\mathrm{a}}$ & $\mathrm{S}$ & $\mathrm{d}^{\mathrm{c}}$ \\
CAM5-MG2 & $\mathrm{S}$ & $\mathrm{S}$ & $\mathrm{p}^{\mathrm{d}}$ \\
CAM5-PNNL & $\mathrm{S}$ & $\mathrm{S}$ & $\mathrm{d}$ \\
CAM5-CLUBB & $\mathrm{S}+$ shallow convective clouds & $\mathrm{S}+$ shallow convective clouds & $\mathrm{d}$ \\
CAM5-CLUBB-MG2 & $\mathrm{S}+$ shallow convective clouds & $\mathrm{S}+$ shallow convective clouds & $\mathrm{p}$ \\
ECHAM6-HAM2 & $\mathrm{S}+$ convective detrainment & $\mathrm{S}$ & $\mathrm{d}$ \\
SPRINTARS & $\mathrm{S}+\mathrm{C}^{\mathrm{b}}$ & $\mathrm{S}+\mathrm{C}$ & $\mathrm{d}$ \\
SPRINTATRS-KK & $\mathrm{S}+\mathrm{C}$ & $\mathrm{S}+\mathrm{C}$ & $\mathrm{d}$ \\
ModelE2-TOMAS & $\mathrm{S}+$ anvil clouds & $\mathrm{S}+$ anvil clouds & $\mathrm{d}$ \\
HadGEM3-UKCA & $\mathrm{S}+\mathrm{C}$ & $\mathrm{S}$ & $\mathrm{p}$ \\
\hline
\end{tabular}

${ }^{a} \mathrm{~S}$ in LWP and Rain stands for stratiform clouds. ${ }^{\mathrm{b}} \mathrm{C}$ in LWP and Rain stands for convective clouds. ${ }^{\mathrm{c}} \mathrm{d}$ in Rain schemes represents

diagnostic rain scheme. ${ }^{\mathrm{d}} \mathrm{p}$ in Rain schemes represents prognostic rain scheme.

and longwave radiative effect of $\sim 27 \mathrm{~W} \mathrm{~m}^{-2}$ ) (Boucher et al., 2013), long integrations are required to produce statistically significant results. The Newtonian relaxation method (nudging) provides a way to estimate AIE within a relatively short integration time, while giving statistically significant results (Lohmann and Hoose, 2009; Kooperman et al., 2012). Nudging here refers to the method of adding a forcing to the prognostic model equations, determined by the difference between a model-computed value and a prescribed value at the same time and model grid-cell, to constrain the model results with prescribed atmospheric conditions. Kooperman et al. (2012) implemented nudging to constrain PD and PI simulations toward identical meteorological fields and found that the use of nudging provided a more stable estimate of AIE in shorter simulations and increased the statistical significance of the anthropogenic aerosol perturbation signal. All simulations used in this study were nudged toward reanalysis winds (year 2006 to 2010) provided by operational forecast centers. Some simulations were further nudged toward reanalysis temperature, but this was discouraged because it might affect the moist convection activities simulated in the model (Zhang et al., 2014). All models were driven by the same IPCC aerosol emissions for years 1850 and 2000 (Lamarque et al., 2010) and 5-year simulations were performed in each case (PI and PD). Sea surface temperature, sea-ice extent and greenhouse gas concentrations are prescribed to climatological values in all simulations. Monthly data were then obtained by averaging over the 5-year integration period.

Only $\omega_{500}$ in PD runs is used to derive dynamical regimes and then these dynamical regimes are applied to PI simulations as well, with the assumption that $\omega_{500}$ does not change much from PI to PD. This assumption is reasonable as both $\mathrm{PD}$ and PI runs were nudged toward the reanalysis data here, which ensures $\omega_{500}$ is very similar between PD and PI.

A total of 10 aerosol-climate models participated in this study. This includes five versions of Community Atmosphere Model (CAM) 5.3, and two versions of SPRINTARS. These models show large differences in their aerosol and cloud treatments. For example, while most models (CAM5, CAM5-PNNL, CAM5-MG2, CAM5CLUBB, CAM5-CLUBB-MG2, ECHAM6-HAM2, and SPRINTARS-KK) use the autoconversion scheme from Khairoutdinov and Kogan (2000, hereafter KK), autoconversion rate in ModelE-TOMAS is independent of cloud droplet number concentration and the Berry scheme (Berry, 1968 ) is used for SPRINTARS. Most models use diagnostic rain schemes, while an updated Morrison and Gettelman (2008) microphysics scheme with a prognostic rain scheme (MG2) (Gettelman et al., 2015) is adopted in CAM5-MG2 and CAM5-MG2-CLUBB. HadGEM3-UKCA also adopts a prognostic rain scheme (Abel and Boutle, 2012). While most models only account for aerosol effects on large-scale stratiform clouds, CAM5-CLUBB and CAM5-CLUBB-MG2 use a higher-order turbulence closure (CLUBB) to unify the treatment of boundary layer turbulence, stratiform clouds, and shallow convection, and therefore include aerosol effects on shallow convection (Bogenschutz et al., 2013). A brief description of each model is provided in Appendix A.

\section{Results}

\subsection{Annual mean}

We first examine the annual climatology in different simulations to get an overall picture of the general differences and/or similarities among these models (details within dynamic regimes are examined in Sect. 3.2). All of the simulations reproduce the general pattern of large-scale circulations $\left(\omega_{500}\right)$ : strong ascending motions within the inter-tropical convergence zone (ITCZ) and subsidence dominating subtropical eastern ocean regions (not shown). The similar patterns of $\omega_{500}$ (due to nudging) in these simulations ensure that dynamic regimes defined by $\omega_{500}$ do not vary much between models. 
Table 2. Global ocean $\left(60^{\circ} \mathrm{S}-60^{\circ} \mathrm{N}\right)$ averages of LWP, column-integrated cloud condensation nuclei (CCN, at $0.1 \%$ supersaturation) concentration, precipitation rate (PRECL), shortwave cloud radiative effect (SCRE) derived from the present-day (PD) cases and the relative change from pre-industrial (PI) to PD of LWP and CCN (d ln LWP and d ln CCN) and the sensitivity of LWP to CCN concentration change $(\lambda, \mathrm{d} \ln \mathrm{LWP} / \mathrm{d} \ln \mathrm{CCN})$ of the $10 \mathrm{GCM}$ simulations.

\begin{tabular}{lrrrrrrr}
\hline Model & $\lambda$ & $\begin{array}{r}\text { LWP } \\
\left(\mathrm{g} \mathrm{m}^{-2}\right)\end{array}$ & $\begin{array}{r}\mathrm{CCN} \\
\left(10^{11} \mathrm{~m}^{-2}\right)\end{array}$ & $\mathrm{d} \ln \mathrm{LWP}$ & $\mathrm{d} \operatorname{lnCCN}$ & $\begin{array}{r}\text { PRECL } \\
\left(\mathrm{mm} \mathrm{day}^{-1}\right)\end{array}$ & $\begin{array}{r}\text { SCRE } \\
\left(\mathrm{W} \mathrm{m}^{-2}\right)\end{array}$ \\
\hline CAM5 & 0.20 & 31.1 & 1.86 & 0.07 & 0.36 & 0.90 & -61.9 \\
CAM5-MG2 & 0.23 & 30.0 & 1.73 & 0.07 & 0.32 & 0.76 & -67.9 \\
CAM5-PNNL & 0.19 & 39.4 & 2.51 & 0.08 & 0.42 & 0.91 & -64.6 \\
CAM5-CLUBB & 0.25 & 35.2 & 1.88 & 0.11 & 0.45 & 1.26 & -57.7 \\
CAM5-CLUBB-MG2 & 0.27 & 47.1 & 1.66 & 0.11 & 0.42 & 1.08 & -70.6 \\
ECHAM6-HAM2 & 0.19 & 84.6 & 2.39 & 0.07 & 0.41 & 1.35 & -54.5 \\
SPRINTARS & 0.01 & 139.1 & 1.07 & 0.00 & 0.43 & 1.42 & -62.6 \\
SPRINTATRS-KK & 0.04 & 98.9 & 1.04 & 0.02 & 0.45 & 1.59 & -57.0 \\
ModelE2-TOMAS & 0.00 & 80.4 & 2.66 & 0.00 & 0.43 & 2.17 & -68.1 \\
HadGEM3-UKCA & 0.03 & 57.1 & 1.01 & 0.01 & 0.67 & 0.87 & -58.9 \\
\hline
\end{tabular}

Table 1 lists the types of clouds included in LWP and rain analyzed in this study and the different rain scheme (prognostic or diagnostic) in these $10 \mathrm{GCM}$ simulations. Table 2 lists global annual means of aerosol, precipitation and cloud parameters in PD simulations and $\lambda$ for each model. Note that all versions of CAM5 calculate LWP only for large-scale clouds while SPRINTARS, SPRINTARS-KK and HadGEM3-UKCA also count LWP from convective clouds. As for ModelE2-TOMAS, LWP includes stratiform anvil clouds that formed from convective detrainment of water vapor and ice. ECHAM6-HAM2 also includes the contribution of convective detrainment of liquid water and ice to stratiform clouds. Also note that CAM5 models with CLUBB include LWP in the shallow convective regimes, which partly explains why these models produce more LWP than their corresponding CAM5 models without CLUBB (Table 2).

There are large differences among global LWP annual means. CAM5-MG2 has the lowest LWP among these simulations $\left(30.0 \mathrm{~g} \mathrm{~m}^{-2}\right)$. The LWP means over oceans are 31.1, 39.4, and $35.2 \mathrm{~g} \mathrm{~m}^{-2}$ in CAM5, CAM5-PNNL, and CAM5-CLUBB, respectively. HadGEM3-UKCA simulates higher LWP (57.1 $\left.\mathrm{g} \mathrm{m}^{-2}\right)$ than all versions of CAM5. LWPs in ModelE2-TOMAS $\left(80.4 \mathrm{~g} \mathrm{~m}^{-2}\right)$ and ECHAM6-HAM2 $\left(84.6 \mathrm{~g} \mathrm{~m}^{-2}\right)$ are greater than the aforementioned GCMs, but less than in SPRINTARS and SPRINTARS-KK (139.1 and $98.9 \mathrm{~g} \mathrm{~m}^{-2}$ respectively) which include LWP from convective clouds. Even though CAM5-CLUBB simulates a higher LWP in storm track regions and ECHAM6-HAM2 produces much more LWP associated with deep convection in the ITCZ, all models here display reasonable patterns of global LWP distributions (not shown).

The differences in $\mathrm{CCN}$ (at $0.1 \%$ supersaturation) among these simulations are not as large as the differences in LWP (Table 2). The global annual mean CCN in CAM5PNNL, which has a different treatment of wet scavenging processes (Wang et al., 2013), is slightly larger than the one in other versions of CAM5. CCN concentrations simulated by CAM5-PNNL, ECHAM6-HAM2, and ModelE2TOMAS are largest among these simulations and are more than twice those simulated by SPRINTARS, SPRINTARSKK and HadGEM3-UKCA, which are the lowest. Since these models are using the same emissions, differences of $\mathrm{CCN}$ between the models are mainly due to different aerosol lifetime between models.

The LWP response to aerosol perturbations, $\lambda$, in ECHAM6-HAM2 (0.19) is close to those derived from three CAM5 configurations (0.20 in CAM5, 0.19 in CAM5PNNL and 0.25 in CAM5-CLUBB). Notice that $\lambda$ in CAM5MG2 and CAM5-CLUBB-MG2 is larger than that in CAM5 and CAM5-CLUBB, respectively, which indicates that the changes of LWP in the models, using the MG2 scheme, are more sensitive to the aerosol perturbations. LWP is much less sensitive to the changes of CCN in SPRINTARS and SPRINTARS-KK with $\lambda$ of 0.01 and 0.04 respectively. $\lambda$ is also small in HadGEM3-UKCA (0.03) due to the large relative increase of $\mathrm{CCN}$ and a small relative increase of LWP. Since the aerosol effect on precipitation formation is turned off in ModelE2-TOMAS (its autoconversion parameterization is not a function of $N_{\mathrm{d}}$ ), LWP barely responds to the increase of $\mathrm{CCN}$ ( $\lambda$ is -0.001$)$. The variation in $\lambda$ closely follows that of the relative enhancement of LWP (dlnLWP), as the variation of the relative enhancement of $\mathrm{CCN}(\mathrm{d} \ln \mathrm{CCN})$ among the simulations is generally much smaller than that of $\mathrm{d} \ln$ LWP.

We should note that large differences in CCN shown in Table 2 do not necessarily correspond to equally large differences in droplet concentration $\left(N_{\mathrm{d}}\right)$, since $N_{\mathrm{d}}$ is primarily dependent on cloud base updraft, which is an extremely uncertain parameter and may vary significantly between the GCMs. It therefore seems reasonable to define $\lambda$ as the change in LWP vs. the change in cloud droplet number concentration $\left(N_{\mathrm{d}}\right)$, which would provide a direct insight 

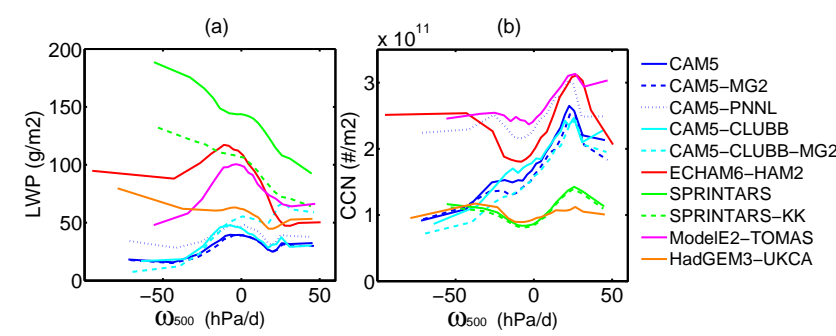

Figure 1. (a) LWP and (b) column-integrated CCN (at $0.1 \%$ supersaturation) as a function of $500 \mathrm{hPa}$ vertical pressure velocity $\left(\omega_{500}\right)$ derived from different models: CAM5 (blue solid line), CAM5MG2 (blue dashed line), CAM5-PNNL (blue dotted line), CAM5CLUBB (cyan solid line), CAM5-CLUBB-MG2 (cyan dashed line), ECHAM6-HAM2 (red solid line), SPRINTARS (green solid line), SPRINTARS-KK (green dashed line), ModelE2-TOMAS (purple solid line) and HadGEM3-UKCA (orange solid line).

into how clouds' response to $N_{\mathrm{d}}$ changes since LWP directly depends on $N_{\mathrm{d}}$, not necessarily on CCN. However, this alternative definition of $\lambda$ as $d \ln L W P / d \ln N_{\mathrm{d}}$ would be difficult to compare with observations, and this also does not directly measure cloud response to anthropogenic aerosols. The interactions between clouds and anthropogenic aerosols arise through a chain of processes, from effects of the CCN on $N_{\mathrm{d}}$ to effects of $N_{\mathrm{d}}$ on cloud water, which can be expressed as $\mathrm{d} \ln \mathrm{LWP} / \mathrm{d} \ln \mathrm{CCN}=\left(\mathrm{d} \ln L W P / \mathrm{d} \ln N_{\mathrm{d}}\right) \cdot\left(\mathrm{d} \ln N_{\mathrm{d}} / \mathrm{d} \ln \mathrm{CCN}\right)$. This chain of processes has now been examined in Ghan et al. (2016) based on the same set of model simulations documented in this study.

\subsection{Regime dependence}

\subsubsection{LWP, CCN, and $\lambda$}

Figure 1 shows LWP and CCN as a function of vertical pressure velocity at $500 \mathrm{hPa}\left(\omega_{500}\right)$ derived from PD simulations. To derive Fig. 1, the 12-month monthly global grid values are first sorted into 20 dynamical regimes according to their $\omega 500$ values, keeping the number of samples in each bin equal. LWP, CCN, and values of other fields for each bin are then calculated from averaging the values of all samples in that particular bin.

In general, SPRINTARS (default and KK) simulates much higher LWP in all dynamic regimes and ECHAM6HAM2/ModelE2-TOMAS in most regimes than different versions of CAM5 runs (default, PNNL, CLUBB and MG2) (Fig. 1a), which is consistent with global means in Table 2. A peak of LWP is found around $\omega_{500}=0 \mathrm{hPa}^{2} \mathrm{day}^{-1}$ in CAM5, ModelE2-TOMAS, and ECHAM6-HAM2. For SPRINTARS, LWP decreases from 190 to $100 \mathrm{~g} \mathrm{~m}^{-2}$ as $\omega_{500}$ increases from -60 to $40 \mathrm{hPa} \mathrm{day}^{-1}$. In all simulations LWP is low in regimes where $\omega_{500}$ is larger than $10 \mathrm{hPa}$ day $^{-1}$, i.e., regimes dominated by low clouds. HadGEM3-UKCA simulates larger LWP than CAM5 especially in ascending

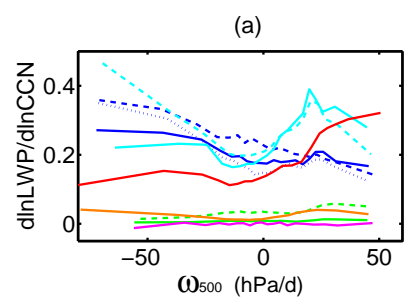

(b)

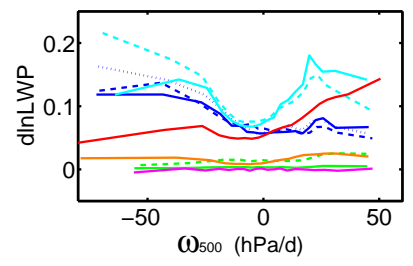

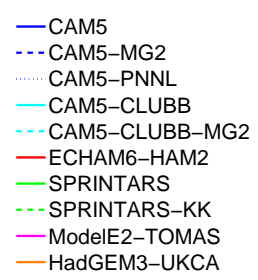

(c)

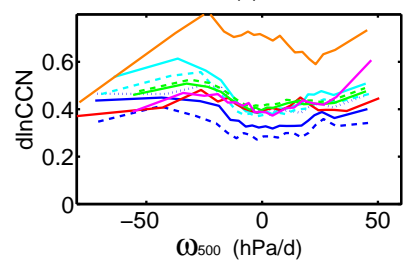

Figure 2. Same as Fig. 1a, but for (a) the sensitivity of LWP to the change of CCN $(\lambda)$, (b) relative enhancement of liquid water path $(\mathrm{d} \ln \mathrm{LWP})$ and $(\mathbf{c})$ relative enhancement of cloud condensation nuclei $(\mathrm{d} \ln \mathrm{CCN})$ from pre-industrial $(\mathrm{PI})$ to present day $(\mathrm{PD})$.

regimes. The model spread of LWP response is larger in the ascending regimes than in the subsiding regimes. This may be partly related to the fact that the types of clouds included in LWP are not the same in different models (Table 1). Figure $1 \mathrm{~b}$ shows that $\mathrm{CCN}$ concentrations peak at around $25 \mathrm{hPaday}^{-1}$ among all the models. This peak is partly caused by little precipitation (and therefore low wet scavenging rate) in subsidence regimes as well as by the fact that these dynamic regimes are located near continents where the sources of anthropogenic aerosols are strong. Furthermore, CCN concentrations are low at around $0 \mathrm{hPaday}^{-1}$, which could be explained by the fact that most regimes around $0 \mathrm{hPaday}^{-1}$ are located over the oceans far away from continents (i.e. remote marine aerosols) and anthropogenic aerosol source regions (figures not shown). Generally, CCN in two versions of SPRINTARS and HadGEM3UKCA is less than other models in most regimes, consistent with Table 2.

All the simulations show positive $\lambda$ within all dynamical regimes (Fig. 2a), which is consistent with the theory proposed by Albrecht (1989) that an increase in aerosols leads to more liquid cloud water. However, $\lambda$ can vary significantly between regimes in CAM5 and ECHAM6-HAM2 (Fig. 2a), which indicates that changes in LWP in response to aerosol perturbations are regime-dependent in these GCMs. For example, $\lambda$ in CAM5-PNNL ranges from 0.35 in strong ascending regions to 0.11 in strong subsidence regions, which means that LWP in strong ascending regimes is more sensitive to aerosol perturbations than in strong subsidence regimes. Exceptions are ModelE2-TOMAS, SPRINTARS (default and SPRINTARS-KK), and HadGEM3-UKCA, in which $\lambda$ is low in magnitude (i.e., LWP changes little in response to the changes of $\mathrm{CCN}$, consistent with the global annual means shown in Table 2). 
We note that although the global means of $\lambda$ in all CAM5 configurations and ECHAM6-HAM2 are close, from 0.19 in ECHAM6-HAM2 to 0.25 in CAM5-CLUBB, $\lambda$ in the different dynamical regimes can differ significantly among these simulations (Fig. 2). For example, LWP in CAM5PNNL is much more sensitive to $\mathrm{CCN}$ perturbations than in ECHAM6-HAM2 in strong ascending regimes; and in strong subsidence regimes, LWP in CAM5-CLUBB and ECHAM6HAM2 is more sensitive than in CAM5-PNNL and CAM5. Models that use the MG2 with prognostic rain scheme (i.e. CAM5-MG2 and CAM5-CLUBB-MG2) simulate larger $\lambda$ than the models that use the default MG scheme in most regimes, only except for strong subsidence regimes. However, generally the shapes of the $\lambda$ distribution are very similar. $\lambda$ in CAM5-CLUBB-MG2 is large in both ascending and subsidence regimes, which explains the largest global $\lambda$ in CAM5-CLUBB-MG2 among all configurations (Table 2). Except for the models producing very low values of $\lambda$ (SPRINTARS, SPRINTARS-KK, ModelE2-TOMAS and HadGEM3-UKCA), $\lambda$ from the other models converges around $0 \mathrm{hPaday}^{-1}$ and then diverges greatly in strong ascending regimes (from 0.10 to 0.46 ) and, to a lesser extent, in strong subsidence regimes. This indicates that it is in regimes with weak vertical velocity where models agree most, while it is in strong ascending and descending regimes where models differ most. The diversity of $\lambda$ within dynamical regimes in different GCMs highlights the need to distinguish different dynamical regimes in studying AIE.

When analyzing the numerator and denominator of $\lambda$ separately, we found that this large spread in $\lambda$ is mainly contributed by the numerator, d lnLWP. d ln LWP ranges from about 0 to 0.22 among the models (Fig. 2b), while the denominator $d \ln C C N$ is more stable than $d \ln L W P$ within dynamical regimes and fluctuates around 0.45 , except for larger d ln CCN in HadGEM3-UKCA (Fig. 2c). In summary, the ratio of d $\ln L W P$ to $d \ln C C N(\lambda)$ therefore changes more consistently with $d \ln L W P$ within dynamical regimes.

The decreasing trends of $\lambda$ with increasing $\omega$ in CAM5, CAM5-MG2, and CAM5-PNNL are similar, which is opposite to the increasing trends derived from ECHAM6-HAM2, CAM5-CLUBB, and CAM5-CLUBB-MG2. It is interesting that the regime-dependence of $\lambda$ simulated by CAM5CLUBB and CAM5-CLUBB-MG2 is quite different from that simulated by CAM5, CAM5-MG2, and CAM5-PNNL even though all these five model versions are originally from CAM5 and share many similarities. In CAM5, CAM5-MG2, and CAM5-PNNL, three separate parameterization schemes are used to treat planetary boundary layer (PBL) turbulence, stratiform cloud macrophysics, and shallow convection. In CAM5-CLUBB and CAM5-CLUBB-MG2, instead, a higher-order turbulence closure, Cloud Layers Unified by Binormals (CLUBB), is adopted to replace these three separate schemes to provide a unified treatment of these processes (Bogenschutz et al., 2013). A major improvement of CAMCLUBB is the better simulation of the transition of stratocu- mulus to trade wind cumulus over subtropical oceans (Bogenschutz et al., 2013). Figure 2a shows that $\lambda$ in CAM5CLUBB and CAM5-CLUBB-MG2 is quite different from that in CAM5 simulations without CLUBB (i.e., CAM5, CAM5-MG2 and CAM5-PNNL) in regimes where $\omega_{500}$ is larger than $10 \mathrm{hPa} \mathrm{day}^{-1}$. Under such suppressed conditions, low clouds such as trade wind cumulus and stratocumulus are typically formed. This higher $\lambda$ might be expected because CAM5-CLUBB formulations apply the MG microphysics (and effects of aerosols on cloud microphysics) to shallow convective regimes. The better representation of low clouds in CAM5-CLUBB, and the representation of double-moment microphysics and AIE in shallow convective regimes from the unified parameterization may help to explain the different behaviors between CAM5 runs with CLUBB (CAM5CLUBB and CAM5-CLUBB-MG2) and CAM5 runs without CLUBB (CAM5, CAM5-MG2 and CAM5-PNNL) in subsidence regimes.

In order to find out the crucial geographic locations of dynamic regimes where dlnLWP differs most in Fig. 2b, we plot the global distribution of annual averaged d lnLWP in different simulations, shown in Fig. 3. The ascending regimes where ECHAM6-HAM2 differs significantly from the two CAM5 configurations (CAM5, CAM5-PNNL) are located over the North Pacific Ocean (from 30 to $60^{\circ} \mathrm{N}$ ), for weak ascending motions and the southern coast of Asia for strong ascending motions. The spatial patterns in ECHAM6-HAM2, CAM5-CLUBB, CAM5-CLUBB-MG2, and HadGEM3-UKCA share some similarities over the northern Pacific Ocean, but the magnitude in CAM5-CLUBB and CAM5-CLUBB-MG2 is larger than in ECHAM6HAM2 and HadGEM3-UKCA. Moreover, not only the spatial pattern but also the magnitude of $d \ln L W P$ in ECHAM6HAM2 differ significantly from those in CAM5, CAM5MG2 and CAM5-PNNL. For the southern coast of Asia where strong ascending motions dominate, all simulations show a relative increase of LWP. However, d $\ln L W P$ in ECHAM6-HAM2 in this region is much smaller than in all CAM5 simulations. This makes dlnLWP, and thus $\lambda$, in ECHAM6-HAM2 much less than in the five CAM5 models (CAM5, CAM5-MG2, CAM5-PNNL, CAM5-CLUBB, and CAM5-CLUBB-MG2) in ascending regimes, as shown in Fig. $2 b$ and $a$.

Despite the fact that SPRINTARS (default and KK), ModelE2-TOMAS, and HadGEM3-UKCA all show almost no relative change of LWP in response to aerosol perturbations, the spatial patterns of d lnLWP in these four simulations shown in Fig. 3 are indeed different from each other. HadGEM3-UKCA simulates larger d $\ln$ LWP in middle northern subtropical oceans, which is similar to CAM5CLUBB and ECHAM6-HAM2 but with smaller magnitude. However, the pattern in SPRINTARS is unlike any model discussed above. SPRINTARS simulates larger d lnLWP over the North Pacific Ocean, the North Atlantic Ocean, and the western coasts of continents than other parts of the 

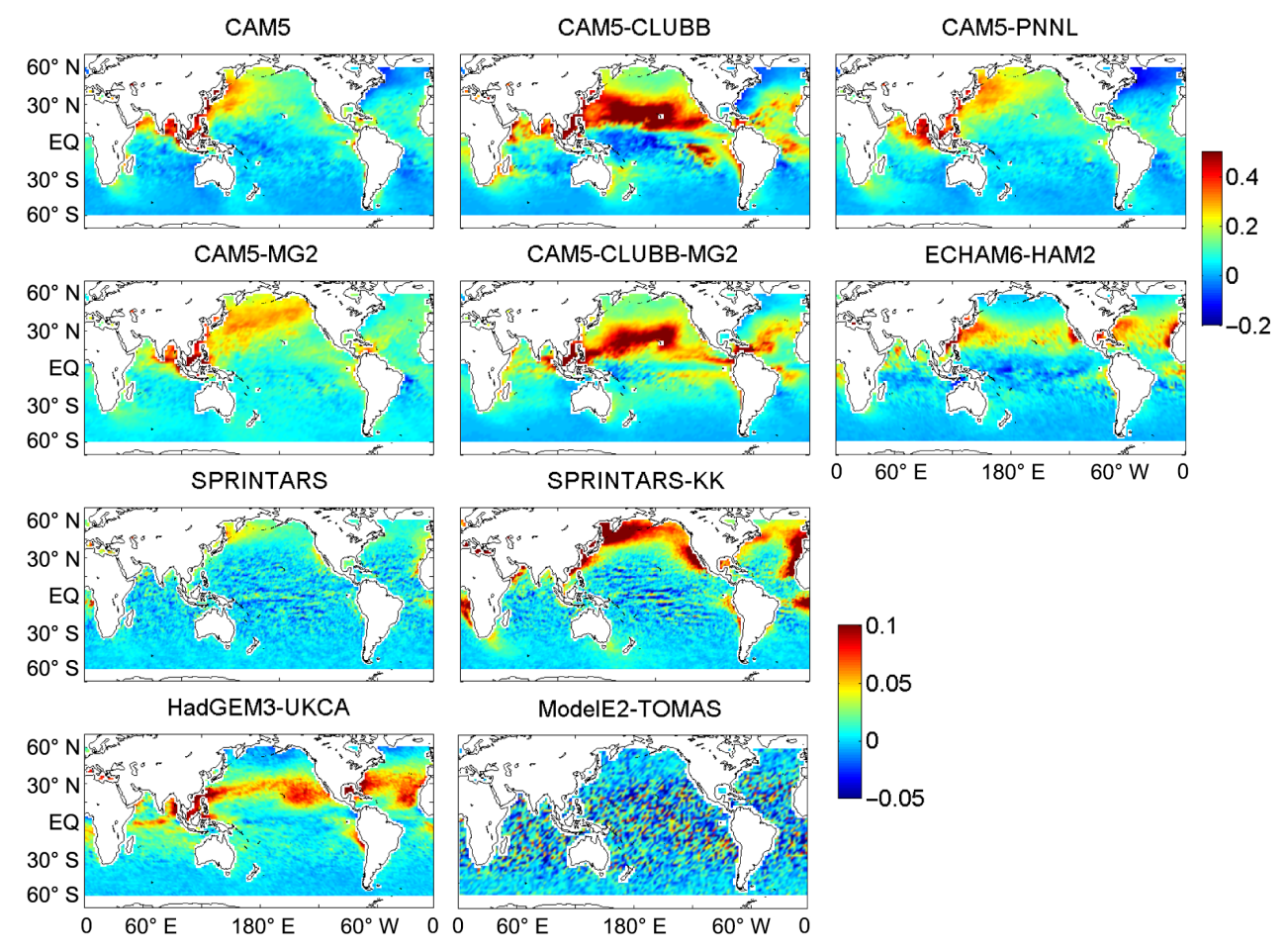

Figure 3. Relative change of annual averaged LWP from PI to PD (d ln LWP) simulations derived from the 10 GCM simulations.

global ocean. SPRINTARS-KK simulates the same pattern as SPRINTARS only with larger values. Meanwhile, $d \ln$ LWP in ModelE2-TOMAS shows no special global pattern and the values are all near zero, which indicates LWP in ModelE2TOMAS has indeed little response to aerosol perturbations as autoconversion rate in ModelE2-TOMAS is not influenced by cloud droplet number concentrations.

Figure 3 shows that the differences in subsidence regimes in Fig. $2 b$ are mainly contributed by middle northern subtropical oceans and western coasts of continents. In middle northern subtropical oceans, the relative changes of LWP in ECHAM6-HAM2, HadGEM3-UKCA and the two CAM5 models with CLUBB (CAM5-CLUBB and CAM5-CLUBBMG2) are much more sensitive to the aerosol perturbations than in the three CAM5 models without CLUBB (CAM5, CAM5-PNNL, and CAM5-MG2), even though d lnLWP in ECHAM6-HAM2 and HadGEM3-UKCA is not as large as that in CAM5-CLUBB and CAM5-CLUBB-MG2. Another difference among these models is in regions dominated by more intensive subsidence, over the western coasts of North America, South America, and Africa. In these regions dlnLWP in ECHAM6-HAM2 and the two CAM5 models with CLUBB is large while it is small in the three CAM5 models without CLUBB.

To examine the cloud lifetime effect in different cloud regimes more specifically, another criterion, lowertropospheric stability ( $\mathrm{LTS}=\theta_{700 \mathrm{~Pa}}-\theta_{\text {surface }}$ ), is added to distinguish stratocumulus from trade wind cumulus regimes, following Medeiros and Stevens (2011). Table 3 lists the criteria of different low cloud types conditionally sampled by $\omega_{500}$ and LTS. The annual mean cloud fractions of each low cloud type in CAM5-CLUBB are shown in Fig. 4; the distributions in other simulations are generally similar to CAM5CLUBB (figures not shown). The cloud type distribution is consistent with satellite observations which show that stratocumuli occur over subtropical oceans near western continents while trade wind cumuli dominate over oceans further away from continents (Medeiros and Stevens, 2011). Figure 4 shows that some differences in d $\ln L W P$ between models shown in Fig. 3 are located at regions dominated by low clouds (i.e., stratocumulus and trade wind cumulus).

The joint distributions of LTS and $\omega_{500}$ over global oceans between $60^{\circ} \mathrm{S}$ and $60^{\circ} \mathrm{N}$ derived from the models are shown in Fig. 5. Note that the bins here are not equally sampled as in previous figures but divided into equal LTS and $\omega$ intervals. LTS ranges from 8 to $24 \mathrm{~K}$ while $\omega$ ranges from -100 to $60 \mathrm{hPa} \mathrm{day}^{-1}$. Instances with slight downward vertical motions and moderate LTS are most frequent.

Figure 5 shows that, though $\omega_{500}$ plays the primary role in determining the $\mathrm{d} \ln \mathrm{LWP} / \mathrm{d} \ln \mathrm{CCN}$ distribution, LTS can reveal further details of the differences among various low cloud types in subsidence regimes. The large $\lambda$ in strong subsidence regimes in ECHAM6-HAM2 and CAM5-CLUBB is mainly caused by stratocumulus and trade wind cumulus. As for regions of ascending motions, LTS is confined between 12 and 14 K. $\lambda$ in CAM5, CAM5-PNNL and CAM5-CLUBB 
Table 3. Criteria used to conditional sampling stratocumulus, transitional clouds, and trade wind cumulus regimes (adopted from Medeiros and Stevens, 2011).

\begin{tabular}{llll}
\hline & Stratocumulus & Transitional clouds & Trade wind cumulus \\
\hline LTS $(\mathrm{K})$ & LTS $\geq 18.5$ & $18.5>\mathrm{LTS} \geq 15.4$ & $15.4>$ LTS $\geq 11.3$ \\
$\omega_{500 \mathrm{hPa}}\left(\mathrm{hPa} \mathrm{day}^{-1}\right)$ & $\omega_{500 \mathrm{hPa}}>10$ & $\omega_{500 \mathrm{hPa}}>10$ & $\omega_{500 \mathrm{hPa}}>10$ \\
\hline
\end{tabular}
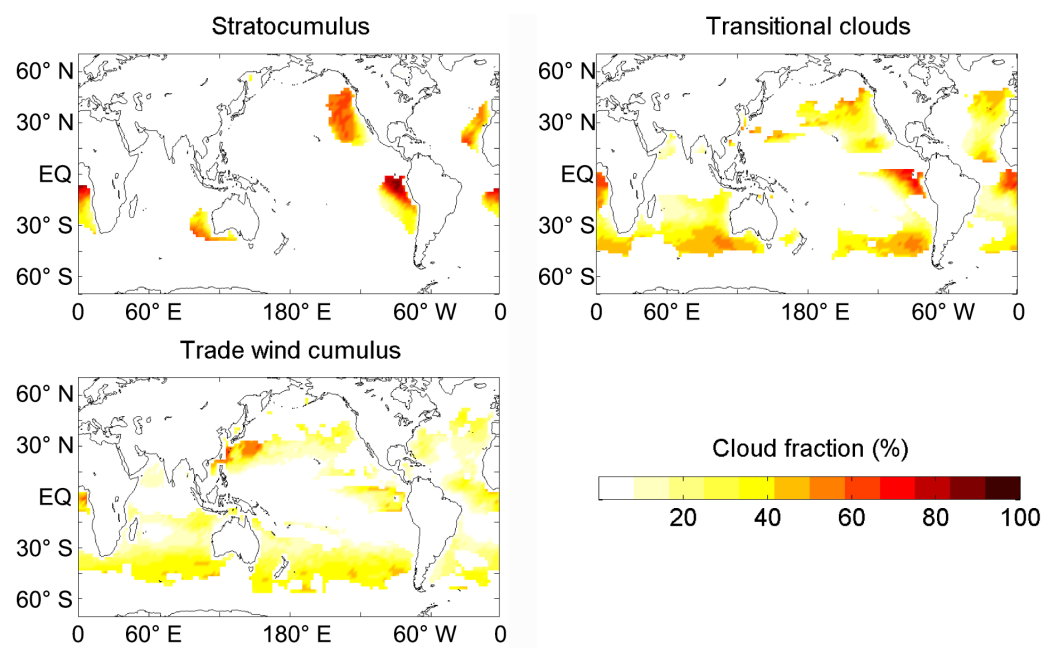

Figure 4. The annual mean cloud fraction (averaged on the months when the regime occurs) of stratocumulus regime (top left), transitional clouds regime (top right) and trade wind cumulus regime (bottom left) derived from PD monthly simulation in CAM5-CLUBB. The definitions of different cloud types are listed in Table 3.

in ascending regimes is larger than in regimes with weak large-scale vertical velocity $\left(\omega_{500}\right.$ around $\left.0 \mathrm{hPa} / \mathrm{d}\right)$ and larger than in ECHAM6-HAM2 in ascending regimes. In ascending regimes, LWP is more sensitive to the change of CCN in the two CAM5 models with the MG2 scheme (CAM5MG2 and CAM5-CLUBB-MG2) than in the two corresponding CAM5 models without the MG2 scheme (CAM5 and CAM5-CLUBB), which is consistent with Fig. 2a. In CAM5CLUBB-MG2, $\lambda$ is larger in transitional cloud regimes than in stratocumulus cloud regimes and trade wind cloud regimes, which is evidently different from the low cloud regimes in CAM5-CLUBB. HadGEM3-UKCA simulates a higher LWP response in transitional clouds and stratocumulus regimes than trade wind cloud regime. It is also interesting to note that $\lambda$ in SPRINTARS and SPRINTARS-KK shows stronger dependence on LTS than on $\omega_{500}$.

\subsubsection{Microphysics process rates and precipitation}

The balance between autoconversion and accretion is found to be critical in determining cloud lifetime effect in climate models (Posselt and Lohmann, 2009; Wang et al., 2012). Autoconversion rate is sensitive to cloud droplet concentration while accretion has little dependence of droplet number. If the role of accretion dominates over autoconversion (with all other effects equal), the effect of aerosols on clouds is expected to be weakened in GCMs (Posselt and Lohmann, 2009; Gettelman et al., 2013). Wang et al. (2012) found that the cloud lifetime effect is highly correlated with the ratio of autoconversion rate to large-scale surface precipitation rate (AUTO/PRECL, where PRECL also includes ice and snow) over global oceans in climate models. AUTO/PRECL for different dynamical regimes is shown in Fig. 6a. Here PD monthly averaged autoconversion rate and surface precipitation rate are used in calculating AUTO/PRECL. Generally the curves of AUTO/PRECL are smoother than $\lambda$ (Figs. 6a and 2a). The ratio from different simulations shows large diversity in ascending regimes and subsidence regimes. In all versions of CAM5 and SPRINTARS the ratio decreases with increasing $\omega_{500}$ in ascending regimes and then increases in descending regimes. The ratio is especially large in CAM5-CLUBB-MG2 and HadGEM3-UKCA in descending regimes. However, the ratio in ECHAM6-HAM2 remains unchanged in ascending regimes and then increases under subsidence. As discussed above, $\lambda$ was shown to be highly correlated with this ratio from global average results (Wang et al., 2012). According to our results, the correlation also applies well for individual dynamical regimes in ECHAM6-HAM2, HadGEM3-UKCA, and CAM-CLUBB, in which the correlation coefficients between $\lambda$ and AUTO/PRECL are 0.98, 0.92 , and 0.86 respectively. However, these high correlation coefficients are not found in other simulations, in which the 

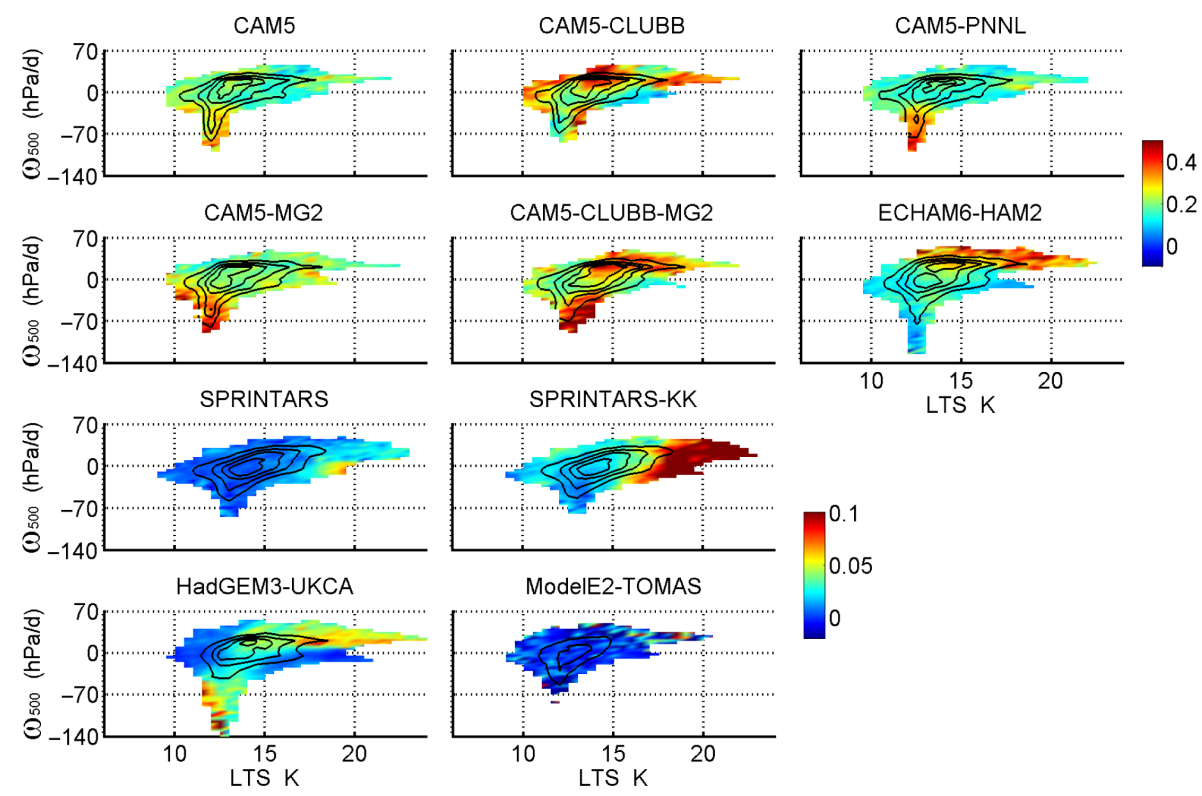

Figure 5. $d \ln L W P / d \ln C C N$ conditioned on vertical motion and LTS derived from the 10 GCM simulations. Solid lines are contours of grid number distribution and each line interval is $20 \%$ of the total counted data.

(a)

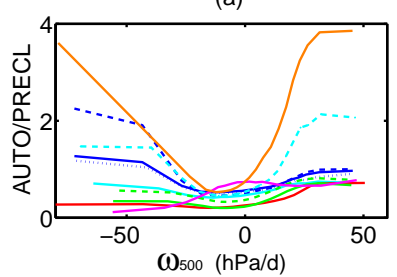

(b)

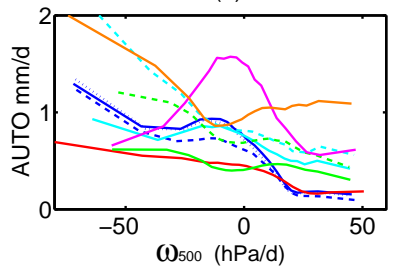

- CAM5 $r=0.6^{*}$

- - CAM5-MG2 $\mathrm{r}=0.537^{*}$

.... CAM5-PNNL $r=0.693^{*}$

CAM5-CLUBB $r=0.855^{\star}$

CAM5-CLUBB-MG2 $r=0.595$

-ECHAM6-HAM2 $\mathrm{r}=0.983^{\circ}$

SPRINTARS $r=0.579^{*}$

SPRINTARS-KK $\mathrm{r}=0.573^{*}$

- ModelE2-TOMAS $\mathrm{r}=0.422$

- HadGEM3-UKCA $r=0.915^{*}$

(c)

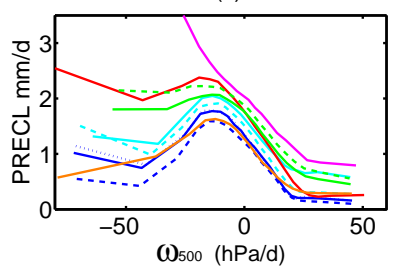

Figure 6. Same as Fig. 1, but for (b) column-integrated autoconversion rate (AUTO), (c) the large-scale surface precipitation rate (PRECL) and (a) their ratio AUTO/PRECL from the 9 GCM simulations. The number marked in each simulation is the corresponding correlation coefficient between AUTO/PRECL and $\lambda$ and number with mark "*" indicates the correlation is significant (at $95 \%$ confidence).

correlation coefficients are lower than 0.7, which indicates that the relationship of AUTO/PRECL and $\lambda$ in these models is changing from regime to regime (i.e., this relationship is regime-dependent).

Wang et al. (2012) and Gettelman et al. (2013) found that the diagnostic rain scheme used in the CAM configurations might overestimate the role of autoconversion over accretion. Using instantaneous microphysical process rates, Gettelman

et al. (2015) found that adding the new microphysics with prognostic precipitation to cloud scheme (MG2) decreases the ratio of autoconversion to accretion. It is in moderate regimes $\left(-20 \mathrm{hPa} \mathrm{day}^{-1}<\omega_{500}<10 \mathrm{hPa} \mathrm{day}^{-1}\right)$ where the result is consistent with Gettelman et al. (2015), which shows larger AUTO/PRECL in CAM5 than CAM5-MG2. However, in other regimes of CAM5 and all regimes of CAM5-CLUBB, adding the prognostic precipitation (MG2) increases the ratio of AUTO/PRECL. The result of larger AUTO/PRECL in some regimes from models with MG2 seems different from the results of Gettelman and Morrison (2015) in idealized tests of MG2 and of Gettelman et al. (2015) in CAM simulations with MG2. We have verified using the same model output from Gettelman et al. (2015) that the difference is not due to the simulations performed. The difference is likely due to the following: (a) the use of instantaneous output in Gettelman et al. (2015) for process rate comparisons while monthly data are used here; (b) microphysics variables and precipitation are sorted by $\omega_{500}$ here while Gettelman et al. (2015) sorted them by LWP, which the microphysics sees, which includes contributions from deep convection; (c) vertical integrals of autoconversion rate are used here while vertical mean values are used in Gettelman et al. (2015).

As discussed in Sect. 1, precipitation is a key process in interactions between aerosols and clouds. A decrease in surface precipitation increases cloud water while a decrease in cloud-top sedimentation increases the entrainment rate and thus dries out LWP when the free troposphere air is dry (Ackerman et al., 2004). Here we investigate the LWP response to aerosol perturbations under low precipitation (monthly aver- 
Table 4. The fractional occurrences of low and high surface precipitation in PD cases over downdraft regimes $\left(\omega_{500}>0 \mathrm{hPa}\right.$ day $\left.{ }^{-1}\right)$ and global oceans and $\lambda$ under these low and high surface precipitation situations only over downdraft regimes. Low precipitation situations refer to monthly surface precipitation rate (PRECL) less than $0.1 \mathrm{~mm} \mathrm{day}^{-1}$ while high precipitation situations refer to PRECL larger than $0.1 \mathrm{~mm}^{\mathrm{day}}{ }^{-1}$.

\begin{tabular}{|c|c|c|c|c|c|c|}
\hline Model & $\begin{array}{r}\lambda^{\mathrm{a}} \\
\text { low, } \\
\text { down }\end{array}$ & $\begin{array}{r}\lambda^{b} \\
\text { high, } \\
\text { down }\end{array}$ & $\begin{array}{r}f^{\mathrm{c}} \\
\text { low, } \\
\text { down }\end{array}$ & $\begin{array}{c}f^{\mathrm{d}} \\
\text { high, } \\
\text { down }\end{array}$ & $\begin{array}{r}f^{\mathrm{e}} \\
\text { low, } \\
\text { glb }\end{array}$ & $\begin{array}{r}f^{f} \\
\text { high, } \\
\text { glb }\end{array}$ \\
\hline CAM5 & 0.21 & 0.19 & 0.47 & 0.54 & 0.27 & 0.73 \\
\hline CAM5-MG2 & 0.19 & 0.24 & 0.57 & 0.43 & 0.39 & 0.61 \\
\hline CAM5-PNNL & 0.17 & 0.17 & 0.48 & 0.52 & 0.28 & 0.72 \\
\hline CAM5-CLUBB & 0.33 & 0.30 & 0.04 & 0.96 & 0.02 & 0.98 \\
\hline CAM5-CLUBB-MG2 & 0.26 & 0.33 & 0.22 & 0.78 & 0.16 & 0.84 \\
\hline ECHAM6-HAM2 & 0.25 & 0.23 & 0.31 & 0.69 & 0.18 & 0.82 \\
\hline SPARINTARS & 0.06 & 0.01 & 0.06 & 0.94 & 0.03 & 0.97 \\
\hline SPARINTARS-KK & 0.24 & 0.04 & 0.05 & 0.95 & 0.03 & 0.97 \\
\hline ModelE2-TOMAS & -0.011 & 0.001 & 0.002 & 0.998 & 0.001 & 0.999 \\
\hline HadGEM3-UKCA & 0.04 & 0.03 & 0.11 & 0.89 & 0.06 & 0.94 \\
\hline
\end{tabular}

aged surface precipitation rate less than $0.1 \mathrm{~mm} \mathrm{day}^{-1}$ ) and high precipitation (monthly averaged surface precipitation rate larger than $0.1 \mathrm{~mm} \mathrm{day}^{-1}$ ). Table 4 lists the occurrence frequency of each situation in different simulations. It shows that instances with low PRECL occurs much less often (from $2.2 \%$ in CAM5-CLUBB to $38.8 \%$ in CAM5-MG2) than those with high PRECL. The occurrence frequency of low precipitation situations is increased with the MG2 scheme (CAM5-MG2 and CAM5-CLUBB-MG2), compared with simulations without MG2. This increase is especially evident in CAM5-CLUBB (from 0.02 in CAM5-CLUBB to 0.16 in CAM5-CLUBB-MG2). This is consistent with Gettelman et al. (2015), who showed that surface precipitation decreases slightly in GCMs with MG2.

Note that low precipitation situations are only found in subsidence regimes $\left(\omega_{500}>0 \mathrm{hPa} \mathrm{day}^{-1}\right)$. Thus, the sensitivity of the LWP response to aerosol change under low and high precipitation is compared only in subsidence regimes. Table 4 also shows $\lambda$ and the fractional occurrences of each precipitation situation in descending regimes. The fractional occurrence of low precipitation increases evidently in subsidence regimes, compared with that over global ocean. We find that the averages of $\lambda$ under low precipitation are larger than those under high precipitation in most models (CAM5, CAM5-PNNL, CAM5-CLUBB, ECHAM6HAM2, SPRINTARS, SPRINTARS-KK and HadGEM3UKCA) (Table 4). This result is different from some LES and single column model (SCM) results showing that smaller $\lambda$ values are found for low surface precipitation rather than high precipitation due to a decrease of LWP in response to increasing CCN (Ackerman et al., 2004; Guo et al., 2011). The decrease in LWP in these previous studies is found to come from the entrainment drying due to increased entrainment from increasing aerosol loading (e.g., Bretherton et al., 2007) and this effect has not been explicitly included in most GCMs. Exceptions are CAM5 runs with the prognostic precipitation scheme MG2 (CAM5-MG2, CAM5-CLUBBMG2). It can be seen from Table 4 that $\lambda$ under low surface precipitation is smaller than under high precipitation only when MG2 scheme is used. It is still unclear what might cause this difference. It is interesting to note that $\lambda$ under low surface precipitation is still higher for HadGEM3UKCA though a prognostic precipitation scheme is applied in HadGEM3-UKCA.

\subsubsection{Shortwave cloud radiative effect}

The shortwave cloud radiative effect (SCRE) is defined as the difference between all-sky and clear sky shortwave radiative fluxes at the top of atmosphere. Here SCRE is adjusted to the "clean-sky" SCRE, which is estimated as a diagnostic with aerosol optical depth set to zero (Ghan, 2013). Recent studies on aerosol indirect effects mostly focus on stratocumulus clouds due to their significant cooling effect (e.g., Lu and Seinfeld, 2005; Bretherton et al., 2007). However, by sorting the change of SCRE (dSCRE) from PI to PD into dynamical regimes, our results suggest that the regimes of ascending motions are as important as the subsidence regimes and in some simulations dSCRE in ascending regimes is even larger than under subsidence regimes (e.g., CAM5-PNNL) (Fig. 7). This suggests that ascending regimes are crucial regimes in studying aerosol climate effect.

We also examined dSCRE contributed by low and high precipitation situations (note that the total dSCRE is the sum 

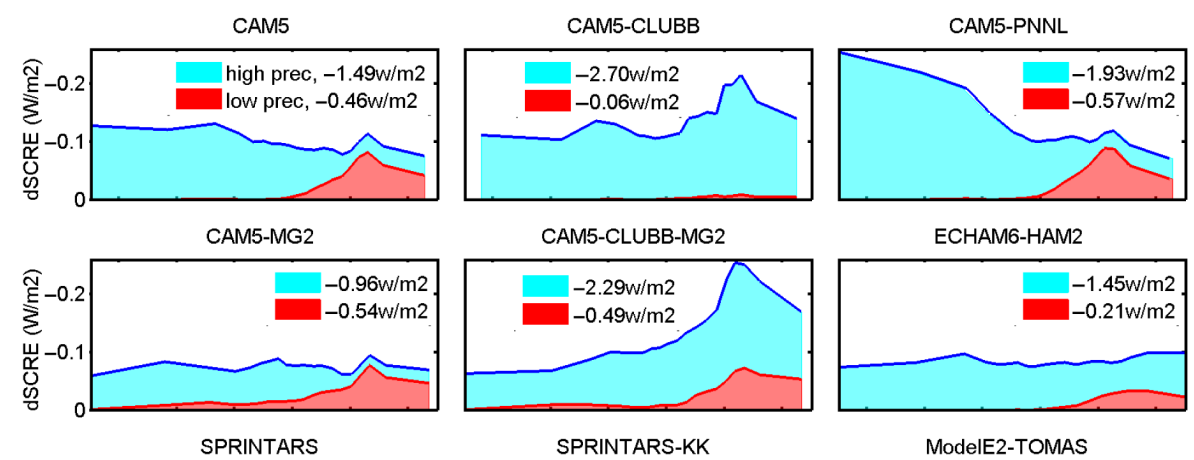

CAM5-CLUBB-MG2

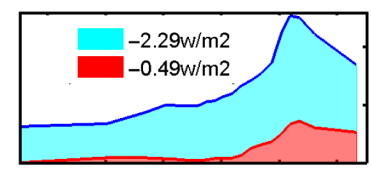

ECHAM6-HAM2

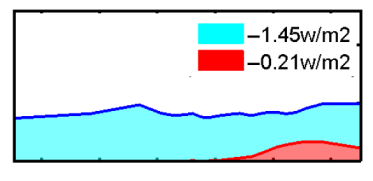

SPRINTARS-KK

ModeIE2-TOMAS
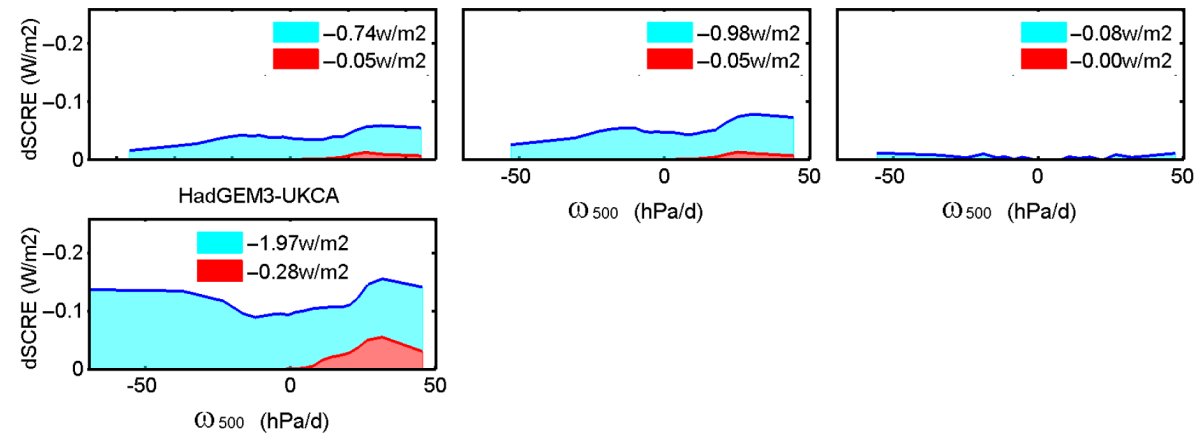

$500(\mathrm{hPa} / \mathrm{d})$

(1) $500(\mathrm{hPa} / \mathrm{d})$

Figure 7. Change in shortwave cloud radiative effect (dSCRE, shown in blue line) from PI to PD as a function of dynamic regimes. Red patches are dSCRE contributed by low precipitation situations while blue patches are by high precipitation situations.

of dSCRE under a low and high precipitation situation). It is found that high precipitation situations constitute most of dSCRE (from $64 \%$ in CAM5-MG2 to nearly $100 \%$ in CAM5-CLUBB, Fig. 7) and the contributions from clouds with low precipitation rates are generally small, ranging from 0 to $36 \%$, due to their low occurrence frequency. dSCRE is reduced by $33 \%$ for high precipitation situations from CAM5 to CAM5-MG2, and $15 \%$ from CAM5-CLUBB to CAM5-CLUBB-MG2 (Fig. 7), consistent with the argument that prognostic precipitation schemes reduce aerosol indirect forcing (Posselt and Lohmann, 2009; Wang et al., 2012; Gettelman and Morrison, 2015). However, adopting a prognostic precipitation scheme is found to increase dSCRE under low precipitation situations. This is partly from the increase in the occurrence frequency of low precipitation instances when MG2 is adopted (Table 4).

Our sensitive tests indicate that results in Table 4 and Fig. 7 can be potentially sensitive to the precipitation threshold applied to separate high precipitation and low precipitation situations (not shown). The occurrence frequency of low precipitation situations increases with increasing threshold and the magnitude of increase can be different for different models. For example, when the precipitation threshold increases from 0.01 to $0.20 \mathrm{~mm} \mathrm{day}^{-1}$, the occurrence frequency of low precipitation situations increases from 2 to $37 \%$ in CAM5-PNNL while it increases from near 0 to $5 \%$ in CAM5-CLUBB. Increasing the precipitation threshold also increases the contribution of low precipitation situations to the total aerosol indirect forcing as the occurrence frequency of low precipitation situations increases. However, our results indicate that the LWP response to aerosol perturbations under low and high precipitation does not change much as the precipitation threshold changes and that high precipitation situations generally contribute more to the total aerosol indirect forcing for precipitation threshold in the range of 0.01 to $0.20 \mathrm{~mm} \mathrm{day}^{-1}$. More work is needed to explore this further, such as how results may be different when instantaneous precipitation data (e.g., 3-hourly data) are used.

\section{Summary}

We have examined the regime-dependence of aerosol indirect effects (AIE) over global oceans (from $60^{\circ} \mathrm{S}$ to $60^{\circ} \mathrm{N}$ ) in several GCMs (CAM5, CAM5-MG2, CAM5PNNL, CAM5-CLUBB, CAM5-CLUBB-MG2, ECHAM6HAM2, SPRINTARS, SPRINTARS-KK, ModelE2-TOMAS and HadGEM3-UKCA). Model results are sorted into different dynamical regimes, characterized by the monthly mean mid-tropospheric $500 \mathrm{hPa}$ vertical pressure velocity $\left(\omega_{500}\right)$, lower-tropospheric stability (LTS, $\theta_{700 \mathrm{hPa}}-\theta_{\text {surface }}$ ), and surface precipitation rate.

The response of liquid water path (LWP) to aerosol perturbations, $\lambda=\mathrm{d} \ln L W P / d \ln C C N$, a metric to quantify cloud lifetime effect of aerosols (Wang et al., 2012), shows a large spread within dynamical regimes among GCMs, although the global means are close. This diversity indicates that the 
aerosol cloud lifetime effect is regime-dependent. It is in strong ascending regimes and subsidence regimes that $\lambda$ differs most between GCMs (Fig. 2a). Stratocumulus regimes have traditionally been the focus for studying aerosol indirect effects because of their significant cooling effect in climate system (e.g., Ackerman et al., 2004; Bretherton et al., 2007; Gettelman et al., 2013). However, our results highlight that regimes with strong large-scale ascent should be another important regime to focus on in the future. Our results indicate that aerosol indirect forcing in regimes of vertical ascent is close to, or even larger than that in low cloud regimes (Fig. 7). Note however that these GCMs do not treat aerosol effects in their representations of deep convection that dominates clouds and LWP in regimes with strong ascent, while new versions of CAM exist where a version of the MG microphysics has been embedded in the deep convective parameterization (Song and Zhang, 2011).

By adding LTS as another criterion, we further separated different low cloud types under large-scale subsidence and revealed some further differences in cloud lifetime effect of aerosols on different types of low clouds. For example, the large $\lambda$ in subsidence regimes in CAM5-CLUBB and ECHAM6-HAM2 comes from both stratocumulus and trade wind cumulus, while in CAM5-CLUBB-MG2 it mostly comes from trade wind cumulus (Fig. 5). It is also interesting to note that the distribution of $\lambda$ in SPRINTARS and SPRINTATSKK is more likely to depend on LTS rather than vertical pressure velocity.

Precipitation is another important factor in understanding simulated aerosol indirect forcing and its spread across models. LWP is more sensitive to CCN change under low precipitation situations (monthly mean surface precipitation rate less than $0.1 \mathrm{~mm} \mathrm{day}^{-1}$ ) than under high precipitation situations (monthly mean surface precipitation rate larger than $0.1 \mathrm{~mm}$ day $^{-1}$ ) in all models except for CAM5 simulations with prognostic rain scheme (MG2) (Table 4). Results derived from large eddy simulation (LES) and single column model (SCM) (e.g., Ackerman et al., 2004; Guo et al., 2011) have shown that $\lambda$ could be negative under low precipitation situations, which indicates that $\lambda$ is expected to be smaller under low precipitation situations. Further efforts are needed to understand the differences among different models and the difference between global model results and results from process-level studies.
Our results indicate that grids with high precipitation contribute most to aerosol indirect forcing (from $64 \%$ in CAM5MG2 to nearly $100 \%$ in CAM5-CLUBB, Fig. 7) and the contributions from model grids with low precipitation are relatively small, ranging from 0 to $36 \%$. Adding prognostic precipitation scheme (MG2) reduces the shortwave cloud radiative effect (SCRE) for high precipitation situations. As low precipitation situations are much less prevalent than high precipitation situations, total SCRE decreases in models with prognostic rain scheme compared to those with a diagnostic rain scheme.

The regime categorization used in this study is derived from monthly mean data. Giving the high variability of precipitation and microphysics processes on short timescales, we acknowledge that instantaneous data (e.g. 3 hourly) might provide more reliable information. For example, instantaneous data may help to reconcile some of the discrepancies between our studies and that of Gettelman et al. (2015) regarding the prognostic rain scheme noted in Sect. 3.2b. However, it is challenging to calculate $\lambda$ and aerosol indirect forcing using instantaneous data. Here $\lambda$ and aerosol indirect forcing are derived from the difference between presentday (PD) and pre-industrial (PI) simulations. Using instantaneous data will not guarantee that the sorted bins of dynamical regimes include the same instances from PI to PD, giving the high variability of instantaneous data. Since the main goal in this manuscript is to demonstrate the importance of examining aerosol indirect effects in different cloud and dynamical regimes, the use of monthly mean data serves this goal well. It is our future plan to carry in-depth analysis to further understand some of the findings documented here, such as the large spread in $\lambda$ in regimes of vertical ascent in different models. For example, LWP response to aerosol perturbation documented in this study may include contributions from mixed-phase and ice clouds. In-depth analysis of cloud macrophysics and microphysics processes will help to improve the understanding of the model uncertainty. 


\section{Appendix A: Global aerosol-climate models}

CAM5: This is the default version of CAM5.3. The moist turbulence scheme is based on Bretherton and Park (2009), which explicitly simulates stratus- radiation-turbulence interactions. The shallow convection scheme is from Park and Bretherton (2009) and the deep convection parameterization is retained from CAM4.0 (Neale et al., 2008). The twomoment cloud microphysics scheme from Morrison and Gettelman (2008) (MG) is used to predict both the mass and number mixing ratios for cloud water and cloud ice with a diagnostic formula for rain and snow. The cloud ice microphysics was further modified to allow ice supersaturation and aerosol effects on ice clouds (Gettelman et al., 2010). The activation of aerosol particles into cloud droplets is parameterized by Abdul-Razzak and Ghan (2000, hereafter ARG) and the autoconversion scheme is based on Khairoutdinov and Kogan (2000) (KK). A modal approach is used to treat aerosols in CAM5 (Liu et al., 2012a; Ghan et al., 2012). Aerosol size distribution can be represented by using either 3 modes or 7 modes, and the default 3-mode treatment is used in this study. Simulations were performed at $1.9^{\circ} \times 2.5^{\circ}$ horizontal resolution with finite volume dynamical core, using 30 vertical levels.

CAM5-PNNL: This is the same as CAM5, but a new unified treatment of vertical transport and in-cloud wet removal processes in convective clouds developed by Wang et al. (2013) is applied. It has a more detailed treatment of aerosol activation in convective updrafts and a mechanism is added for laterally entrained aerosols to be activated and then removed. In addition, a few other changes have been introduced to stratiform cloud wet scavenging processes in CAM5-PNNL to improve the fidelity of the aerosol simulation, including the vertical distribution of aerosols and their transport to remote regions (Wang et al., 2013).

CAM5-MG2: This is the same as CAM5, but the original two-moment MG scheme with diagnostic treatment for rain and snow in CAM5 is replaced by the updated MG scheme (MG2) with prognostic scheme for rain and snow (Gettelman et al., 2015).

CAM5-CLUBB: This is the same as CAM5, but the separate treatments of boundary layer turbulence, large-scale cloud macrophysics and shallow convection in CAM5 is replaced by CLUBB, a higher-order turbulence closure that unifies these different treatments (Bogenschutz et al., 2013). This therefore includes aerosol effects on shallow convection.

CAM5-CLUBB-MG2: This is the same as CAM5CLUBB, but the MG2 scheme with prognostic rain and snow treatment replaces the original MG scheme with diagnostic rain and snow treatment (Gettelman et al., 2015). This also includes aerosol effects on shallow convection.

ECHAM6-HAM2: ECHAM-HAMMOZ (echam6.1ham2.2-moz0.9) is a global aerosol-chemistry climate model. In this study only the global aerosol-climate model part of ECHAM-HAMMOZ is used and for the sake of brevity referred to as ECHAM6-HAM2 (Neubauer et al., 2014). It consists of the general circulation model ECHAM6 (Stevens et al., 2013) coupled to the latest version of the aerosol module HAM2 (Stier et al., 2005; Zhang et al., 2012) and uses a two-moment cloud microphysics scheme that includes prognostic equations for the cloud droplet and ice crystal number concentrations as well as cloud water and cloud ice (Lohmann et al., 2007; Lohmann and Hoose, 2009). The activation of aerosol articles into cloud droplets is parameterized by Lin and Leaitch (1997) and the autoconversion scheme is based on the KK scheme. Cumulus convection is represented by the parameterization of Tiedtke (1989) with modifications by Nordeng (1994) for deep convection. Aerosol effects on convective clouds are not included, but there is a dependence of cloud droplets detrained from convective clouds on aerosol. Simulations were performed at $\mathrm{T} 63\left(1.9^{\circ} \times 1.9^{\circ}\right)$ spectral resolution using 31 vertical levels (L31).

SPRINTARS: SPRINTARS (Takemura et al., 2005) is a global aerosol transport-climate model based on a general circulation model, MIROC (Watanabe et al., 2010). In this study, the horizontal and vertical resolutions are T106 $\left(1.125^{\circ} \times\right.$ approx. $\left.1.125^{\circ}\right)$ and 56 layers, respectively. SPRINTARS is coupled with the radiation and cloud microphysics schemes in MIROC to calculate the aerosol-radiation and aerosol-cloud interactions. A prognostic scheme for determining the cloud droplet and ice crystal number concentrations is introduced (Takemura et al., 2009). The default autoconversion scheme in MIROC-SPRINTARS is based on Berry (1968), and the activation of aerosol particles into cloud droplet is based on the ARG scheme.

SPRINTARS-KK: This is the same as SPRINTARS, but the default autoconversion scheme in SPRINTARS is replaced with the KK autoconversion scheme.

ModelE2-TOMAS: ModelE2-TOMAS is a global-scale atmospheric chemistry-climate model, which consists of the state-of-the-art NASA GISS ModelE2 general circulation model (Schmidt et al., 2014) coupled to the TwO-Moment Aerosol Sectional (TOMAS) microphysics model (Lee and Adams, 2012; Lee et al., 2015). ModelE2-TOMAS has $2^{\circ}$ latitude by $2.5^{\circ}$ longitude resolution, with 40 vertical hybrid sigma layers from the surface to $0.1 \mathrm{hPa}(80 \mathrm{~km})$. In the model, clouds are distinguished into convective and largescale stratiform clouds. The clouds parameterizations are similar to Del Genio and Yao (1993) and Del Genio et al. (1996) but have been improved in several respects (see details in Schmidt et al., 2014, 2006). Using a prognostic treatment of cloud droplet number concentration (CDNC) from Morrison and Gettleman (2008), ModelE2-TOMAS represents the first aerosol indirect effects only on largescale stratiform clouds (Menon et al., 2010). In ModelE2TOMAS, CDNC and a critical supersaturation are computed using a physical-based activation parameterization from Nenes and Seinfeld (2003) with a model updraft veloc- 
ity that is computed based on a large-scale vertical velocity and sub-grid velocity.

HadGEM3-UKCA: HadGEM3-UKCA is a global composition climate model (http://www.ukca.ac.uk). It consists of the third generation of the Hadley Centre Global Environmental Model (Hewitt et al., 2011) developed at the UK Met Office. This general circulation model is non-hydrostatic and uses a semi-Lagrangian transport scheme. We are using the atmospheric configuration: General Atmosphere (GA) 4.0 as documented in Walters et al., (2014), except for the addition of the UKCA aerosol and chemistry scheme which is fully coupled with the radiation scheme of HadGEM3 (Bellouin et al., 2013). UKCA is a two-moment pseudo-modal scheme which carries both aerosol number concentration and component mass as prognostic tracers. It calculates the evolution of five aerosol species, sulfate, particulate organic matter, black carbon, sea salt and dust, in both internally and externally mixed particles. The aerosol scheme in UKCA is based on the Global Model of Aerosol Processes (GLOMAP-mode, Mann et al., 2010). The main exception is that dust is calculated separately using 6 size bins. UKCA hence only considers 5 modes. The tropospheric chemistry part of UKCA is described in O'Connor et al. (2014). HadGEM3 uses a prognostic treatment of rain formulation (Abel and Boutle, 2012) and employs a prognostic cloud fraction and condensation cloud scheme (PC2) (Wilson et al., 2008), in which the cloud droplet number concentration is diagnosed from the expected number of aerosols that are available to activate at each timestep (West et al., 2014). Cumulus convection is represented by a mass flux convection scheme based on Gregory and Rowntree (1990) with various extensions (Walters et al., 2014). Simulations were performed at N96L85 resolution, a regular $1.25^{\circ}$ latitude $\times 1.875^{\circ}$ longitude grid in the horizontal, with 85 hybrid-height vertical levels. 
Acknowledgements. M. Wang acknowledged the support from the Jiangsu Province Specially-appointed professorship grant and the One Thousand Young Talents Program and the National Natural Science Foundation of China (41575073). The contribution from Pacific Northwest National Laboratory was supported by the US Department of Energy (DOE), Office of Science, Decadal and Regional Climate Prediction using Earth System Models (EaSM program). H. Wang acknowledges support by the DOE Earth System Modeling program. The Pacific Northwest National Laboratory is operated for the DOE by Battelle Memorial Institute under contract DE-AC06-76RLO 1830. The ECHAM-HAMMOZ model is developed by a consortium composed of ETH Zurich, Max Planck Institut für Meteorologie, Forschungszentrum Jülich, University of Oxford, the Finnish Meteorological Institute and the Leibniz Institute for Tropospheric Research, and managed by the Center for Climate Systems Modeling (C2SM) at ETH Zurich. D. Neubauer gratefully acknowledges the support by the Austrian Science Fund (FWF): J 3402-N29 (Erwin Schrödinger Fellowship Abroad). The Center for Climate Systems Modeling (C2SM) at ETH Zurich is acknowledged for providing technical and scientific support. This work was supported by a grant from the Swiss National Supercomputing Centre (CSCS) under project ID s431. D. G. Partridge would like to acknowledge support from the UK Natural Environment Research Council project ACID-PRUF (NE/I020148/1) as well as thanks to N. Bellouin for useful discussions during the course of this work. The development of GLOMAP-mode within HadGEM is part of the UKCA project, which is supported by both NERC and the Joint DECC/Defra Met Office Hadley Centre Climate Programme (GA01101). We acknowledge use of the MONSooN system, a collaborative facility supplied under the Joint Weather and Climate Research Programme, a strategic partnership between the Met Office and the Natural Environment Research Council. P. Stier would like to acknowledge support from the European Research Council under the European Union's Seventh Framework Programme (FP7/2007-2013) / ERC grant agreement no. FP7-280025.

Edited by: P. Chuang

\section{References}

Abel, S. J. and Boutle, I. A.: An improved representation of the raindrop size distribution for single-moment microphysics schemes, Q. J. Roy. Meteor. Soc., 138, 2151-2162, doi:10.1002/qj.1949, 2012.

Abdul-Razzak, H. and Ghan, S. J.: A parameterization of aerosol activation 2. Multiple aerosol types, J. Geophys. Res., 105, 68376844, 2000.

Ackerman, A. S., Kirkpatrick, M. P., Stevens, D. E., and Toon, O. B.: The impact of humidity above stratiform clouds on indirect aerosol climate forcing, Nature, 432, 1014-1017, doi:10.1038/nature03174, 2004.

Albrecht, B. A.: Aerosols, cloud microphysics, and fractional cloudiness, Science, 245, 1227-1230, doi:10.1126/science.245.4923.1227, 1989.

Andreae, M. O., Rosenfeld, D., Artaxo, P., Costa, A. A., Frank, G. P., Longo, K. M., and Silva-Dias, M. A. F.: Smok- ing rain clouds over the Amazon, Science, 303, 1337-1342, doi:10.1126/science.1092779, 2004.

Bellouin, N., Mann, G. W., Woodhouse, M. T., Johnson, C., Carslaw, K. S., and Dalvi, M.: Impact of the modal aerosol scheme GLOMAP-mode on aerosol forcing in the Hadley Centre Global Environmental Model, Atmos. Chem. Phys., 13, 30273044, doi:10.5194/acp-13-3027-2013, 2013.

Berry, E. X.: Modification of the warm rain process, Proc. First Natl. Conf. Weather Modification, American Meteorological Society, State University of New York, Albany, 81-88, 1968.

Bogenschutz, P. A., Gettelman, A., Morrison, H., Larson, V. E., Craig, C., and Schanen, D. P.: Higher-Order Turbulence Closure and Its Impact on Climate Simulations in the Community Atmosphere Model, J. Climate, 26, 9655-9676, doi:10.1175/jcli-d-13$00075.1,2013$.

Bony, S. and Dufresne, J. L.: Marine boundary layer clouds at the heart of tropical cloud feedback uncertainties in climate models, Geophys. Res. Lett., 32, L20806, doi:10.1029/2005gl023851, 2005.

Bony, S., Dufresne, J. L., Le Treut, H., Morcrette, J. J., and Senior, C.: On dynamic and thermodynamic components of cloud changes, Clim. Dynam., 22, 71-86, doi:10.1007/s00382-0030369-6, 2004.

Boucher, O., Randall, D., Artaxo, P., Bretherton, C., Feingold, G., Forster, P., Kerminen, V.-M., Kondo, Y., Liao, H., Lohmann, U., Rasch, P., Satheesh, S. K., Sherwood, S., Stevens, B., and Zhang, X. Y.: Clouds and Aerosols, in: Climate Change 2013: The Physical Science Basis. Contribution of Working Group I to the Fifth Assessment Report of the Intergovernmental Panel on Climate Change, edited by: Stocker, T. F., Qin, D., Plattner, G.-K., Tignor, M., Allen, S. K., Boschung, J., Nauels, A., Xia, Y., Bex V., and Midgley, P. M., Cambridge University Press, Cambridge, United Kingdom and New York, NY, USA, 2013.

Bretherton, C. S. and Park, S.: A New Moist Turbulence Parameterization in the Community Atmosphere Model, J. Climate, 22, 3422-3448, doi:10.1175/2008jcli2556.1, 2009.

Bretherton, C. S., Blossey, P. N., and Uchida, J.: Cloud droplet sedimentation, entrainment efficiency, and subtropical stratocumulus albedo, Geophys. Res. Lett., 34, L03813, doi:10.1029/2006gl027648, 2007.

Chen, Y.-C., Christensen, M. W., Stephens, G. L., and Seinfeld, J. H.: Satellite-based estimate of global aerosol-cloud radiative forcing by marine warm clouds, Nat. Geosci., 7, 643-646, doi:10.1038/ngeo2214, 2014.

Coakley, J. A. and Walsh, C. D.: Limits to the aerosol indirect radiative effect derived from observations of ship tracks, J. Atmos. Sci., 59, 668-680, doi:10.1175/15200469(2002)059<0668:Ittair>2.0.co;2, 2002.

Del Genio, A. D. and Yao, M.-S.: Efficient cumulus parameterization for long-term climate studies: The GISS scheme, in: The Representation of Cumulus Convection in Numerical Models, AMS Meteorol. Monogr., Vol. 46, edited by: Emanuel, K. A. and Raymond, D. A., 181-184, Am. Meteorol. Soc., Washington D.C., 1993.

Del Genio, A. D., Yao, M. S., Kovari, W., and Lo, K. K.: A prognostic cloud water parameterization for general circulation models, J. Climate, 9, 270-304, 1996.

Gettelman, A. and Morrison, H.: Advanced Two-Moment Bulk Microphysics for Global Models. Part I: Off-Line Tests and 
Comparison with Other Schemes, J. Climate, 28, 1268-1287, doi:10.1175/JCLI-D-14-00102.1, 2015.

Gettelman, A., Liu, X., Ghan, S. J., Morrison, H., Park, S., Conley, A. J., Klein, S. A., Boyle, J., Mitchell, D. L., and Li, J. L. F.: Global simulations of ice nucleation and ice supersaturation with an improved cloud scheme in the Community Atmosphere Model, J. Geophys. Res.-Atmos., 115, D18216, doi:10.1029/2009jd013797, 2010.

Gettelman, A., Morrison, H., Terai, C. R., and Wood, R.: Microphysical process rates and global aerosol-cloud interactions, Atmos. Chem. Phys., 13, 9855-9867, doi:10.5194/acp-13-98552013, 2013.

Gettelman, A., Morrison, H., Santos, S., Bogenschutz, P., and Caldwell, P. M.: Advanced Two-Moment Bulk Microphysics for Global Models. Part II: Global Model Solutions and Aerosol-Cloud Interactions, J. Climate, 28, 1288-1307, doi:10.1175/JCLI-D-14-00103.1, 2015.

Ghan, S. J.: Technical Note: Estimating aerosol effects on cloud radiative forcing, Atmos. Chem. Phys., 13, 9971-9974, doi:10.5194/acp-13-9971-2013, 2013.

Ghan, S. J., Liu, X., Easter, R. C., Zaveri, R., Rasch, P. J., Yoon, J. H., and Eaton, B.: Toward a Minimal Representation of Aerosols in Climate Models: Comparative Decomposition of Aerosol Direct, Semidirect, and Indirect Radiative Forcing, J. Climate, 25, 6461-6476, 10.1175/jcli-d-11-00650.1, 2012.

Ghan, S., Wang, M., Zhang, S., Ferrachat, S., Gettelman, A., Griesfeller, J., Kipling, Z., Lohmann, U., Morrison, H., Neubauer, D., Partridge, D. G., Stier, P., Takemura, T., Wang, H., and Zhang, $\mathrm{K}$.: Challenges in constraining anthropogenic aerosol effects on cloud radiative forcing using present-day spatiotemporal variability, P. Natl. Acad. Sci. USA, doi:10.1073/pnas.1514036113, online first, 2016.

Gregory, D. and Rowntree, P. R.: A massflux convection scheme with representation of cloud ensemble characteristics and stability dependent closure, Mon. Weather Rev., 118, 1483-1506, doi:10.1175/1520-0493(1990)118<1483:AMFCSW>2.0.CO;2, 1990.

Gryspeerdt, E. and Stier, P.: Regime-based analysis of aerosolcloud interactions, Geophys. Res. Lett., 39, L21802, doi:10.1029/2012g1053221, 2012.

Gryspeerdt, E., Stier, P., and Grandey, B. S.: Cloud fraction mediates the aerosol optical depth-cloud top height relationship, Geophys. Res. Lett., 41, 3622-3627, doi:10.1002/2014g1059524, 2014a.

Gryspeerdt, E., Stier, P., and Partridge, D. G.: Links between satellite-retrieved aerosol and precipitation, Atmos. Chem. Phys., 14, 9677-9694, doi:10.5194/acp-14-9677-2014, 2014 b.

Gryspeerdt, E., Stier, P., and Partridge, D. G.: Satellite observations of cloud regime development: the role of aerosol processes, Atmos. Chem. Phys., 14, 1141-1158, doi:10.5194/acp-14-11412014, 2014c.

Guo, H., Golaz, J. C., and Donner, L. J.: Aerosol effects on stratocumulus water paths in a PDF-based parameterization, Geophys. Res. Lett., 38, L17808, doi:10.1029/2011g1048611, 2011.

Guo, H., Golaz, J. C., Donner, L. J., Wyman, B., Zhao, M., and Ginoux, P.: CLUBB as a unified cloud parameterization: Opportunities and challenges, Geophys. Res. Lett., 42, 4540-4547, doi:10.1002/2015GL063672, 2015.
Guo, Z., Wang, M. H., Qian, Y., Larson, V. E., Ghan, S., Ovchinnikov, M., Bogenschutz, P. A., Gettelman, A., and Zhou, T. J.: Parametric behaviors of CLUBB in simulations of low clouds in the Community Atmosphere Model (CAM), J. Adv. Model. Earth Syst., 7, 1005-1025, doi:10.1002/2014ms000405, 2015.

Hewitt, H. T., Copsey, D., Culverwell, I. D., Harris, C. M., Hill, R. S. R., Keen, A. B., McLaren, A. J., and Hunke, E. C.: Design and implementation of the infrastructure of HadGEM3: the nextgeneration Met Office climate modelling system, Geosci. Model Dev., 4, 223-253, doi:10.5194/gmd-4-223-2011, 2011.

IPCC: Climate Change 2013: The Physical Science Basis. Contribution of Working Group I to the Fifth Assessment Report of the Intergovernmental Panel on Climate Change, edited by: Stocker, T. F., Qin, D., Plattner, G.-K., Tignor, M., Allen, S. K., Boschung, J., Nauels, A., Xia, Y., Bex, V., and Midgley, P. M., Cambridge University Press, Cambridge, United Kingdom and New York, NY, USA, 1535 pp., 2013

Kaufman, Y. J., Koren, I., Remer, L. A., Rosenfeld, D., and Rudich, Y.: The effect of smoke, dust, and pollution aerosol on shallow cloud development over the Atlantic Ocean, P. Natl. Acad. Sci. USA, 102, 11207-11212, doi:10.1073/pnas.0505191102, 2005.

Khairoutdinov, M. and Kogan, Y.: A new cloud physics parameterization in a large-eddy simulation model of marine stratocumulus, Mon. Weather Rev., 128, 229-243, doi:10.1175/15200493(2000)128<0229:ancppi>2.0.co;2, 2000.

Kooperman, G. J., Pritchard, M. S., Ghan, S. J., Wang, M. H., Somerville, R. C. J., and Russell, L. M.: Constraining the influence of natural variability to improve estimates of global aerosol indirect effects in a nudged version of the Community Atmosphere Model 5, J. Geophys. Res.-Atmos., 117, D23204, doi:10.1029/2012jd018588, 2012.

Lamarque, J.-F., Bond, T. C., Eyring, V., Granier, C., Heil, A., Klimont, Z., Lee, D., Liousse, C., Mieville, A., Owen, B., Schultz, M. G., Shindell, D., Smith, S. J., Stehfest, E., Van Aardenne, J., Cooper, O. R., Kainuma, M., Mahowald, N., McConnell, J. R., Naik, V., Riahi, K., and van Vuuren, D. P.: Historical (1850-2000) gridded anthropogenic and biomass burning emissions of reactive gases and aerosols: methodology and application, Atmos. Chem. Phys., 10, 7017-7039, doi:10.5194/acp10-7017-2010, 2010.

Lebo, Z. J. and Feingold, G.: On the relationship between responses in cloud water and precipitation to changes in aerosol, Atmos. Chem. Phys., 14, 11817-11831, doi:10.5194/acp-1411817-2014, 2014.

Lee, Y.-H. and Adams, P. J.: A fast and efficient version of the TwO-Moment Aerosol Sectional (TOMAS) global aerosol microphysics model, Aerosol. Sci. Tech., 46, 678-689, doi:10.1080/02786826.2011.643259, 2012.

Lee, Y. H., Adams, P. J., and Shindell, D. T.: Evaluation of the global aerosol microphysical ModelE2-TOMAS model against satellite and ground-based observations, Geosci. Model Dev., 8, 631-667, doi:10.5194/gmd-8-631-2015, 2015.

Lin, H. and Leaitch, W. R.: Development of an in-cloud aerosol activation parameterization for climate modelling, in: Proceedings of the WMO Workshop on Measurement of Cloud Properties for Forecasts of Weather, Air Quality and Climate, World Meteorol. Organ., Geneva, 328-335, 1997.

Liu, X., Easter, R. C., Ghan, S. J., Zaveri, R., Rasch, P., Shi, X., Lamarque, J.-F., Gettelman, A., Morrison, H., Vitt, F., Conley, 
A., Park, S., Neale, R., Hannay, C., Ekman, A. M. L., Hess, P., Mahowald, N., Collins, W., Iacono, M. J., Bretherton, C. S., Flanner, M. G., and Mitchell, D.: Toward a minimal representation of aerosols in climate models: description and evaluation in the Community Atmosphere Model CAM5, Geosci. Model Dev., 5, 709-739, doi:10.5194/gmd-5-709-2012, 2012a.

Liu, X., Shi, X., Zhang, K., Jensen, E. J., Gettelman, A., Barahona, D., Nenes, A., and Lawson, P.: Sensitivity studies of dust ice nuclei effect on cirrus clouds with the Community Atmosphere Model CAM5, Atmos. Chem. Phys., 12, 12061-12079, doi:10.5194/acp-12-12061-2012, 2012 b.

Lohmann, U. and Hoose, C.: Sensitivity studies of different aerosol indirect effects in mixed-phase clouds, Atmos. Chem. Phys., 9, 8917-8934, doi:10.5194/acp-9-8917-2009, 2009.

Lohmann, U., Stier, P., Hoose, C., Ferrachat, S., Kloster, S., Roeckner, E., and Zhang, J.: Cloud microphysics and aerosol indirect effects in the global climate model ECHAM5-HAM, Atmos. Chem. Phys., 7, 3425-3446, doi:10.5194/acp-7-3425-2007, 2007.

Lu, M. L. and Seinfeld, J. H.: Study of the aerosol indirect effect by large-eddy simulation of marine stratocumulus, J. Atmos. Sci., 62, 3909-3932, doi:10.1175/jas3584.1, 2005.

Ma, P.-L., Rasch, P. J., Wang, M., Wang, H., Ghan, S. J., Easter, R. C., Gustafson, W. I., Liu, X., Zhang, Y., and Ma, H.-Y.: How does increasing horizontal resolution in a global climate model improve the simulation of aerosol-cloud interactions?, Geophys. Res. Lett., 42, 5058-5065, doi:10.1002/2015GL064183, 2015.

Mann, G. W., Carslaw, K. S., Spracklen, D. V., Ridley, D. A., Manktelow, P. T., Chipperfield, M. P., Pickering, S. J., and Johnson, C. E.: Description and evaluation of GLOMAP-mode: a modal global aerosol microphysics model for the UKCA composition-climate model, Geosci. Model Dev., 3, 519-551, doi:10.5194/gmd-3-519-2010, 2010.

Matsui, T., Masunaga, H., Kreidenweis, S. M., Pielke, R. A., Tao, W. K., Chin, M., and Kaufman, Y. J.: Satellite-based assessment of marine low cloud variability associated with aerosol, atmospheric stability, and the diurnal cycle, J. Geophys. Res.-Atmos., 111, D17204, doi:10.1029/2005jd006097, 2006.

Medeiros, B. and Stevens, B.: Revealing differences in GCM representations of low clouds, Clim. Dynam., 36, 385-399, doi:10.1007/s00382-009-0694-5, 2011.

Menon, S., Koch, D., Beig, G., Sahu, S., Fasullo, J., and Orlikowski, D.: Black carbon aerosols and the third polar ice cap, Atmos. Chem. Phys., 10, 4559-4571, doi:10.5194/acp-10-4559-2010, 2010.

Morrison, H. and Gettelman, A.: A new two-moment bulk stratiform cloud microphysics scheme in the Community Atmosphere Model, version 3 (CAM3). Part I: Description and numerical tests, J. Climate, 21, 3642-3659, 2008.

Neale, R. B., Richter, J. H., and Jochum, M.: The Impact of Convection on ENSO: From a Delayed Oscillator to a Series of Events, J. Climate, 21, 5904-5924, doi:10.1175/2008jcli2244.1, 2008.

Nenes, A. and Seinfeld, J. H.: Parameterization of cloud droplet formation in global climate models, J. Geophys. Res.-Atmos., 108, 4415, doi:10.1029/2002jd002911, 2003.

Neubauer, D., Lohmann, U., Hoose, C., and Frontoso, M. G.: Impact of the representation of marine stratocumulus clouds on the anthropogenic aerosol effect, Atmos. Chem. Phys., 14, 1199712022, doi:10.5194/acp-14-11997-2014, 2014.
Nordeng, T. E.: Extended versions of the convective parametrization scheme at ECMWF and their impact on the mean and transient activity of the model in the tropics, ECMWF Research Department, Technical Momorandum 206, European Centre for Medium-range Weather Forecast, Reading, UK, 1994.

O'Connor, F. M., Johnson, C. E., Morgenstern, O., Abraham, N. L., Braesicke, P., Dalvi, M., Folberth, G. A., Sanderson, M. G., Telford, P. J., Voulgarakis, A., Young, P. J., Zeng, G., Collins, W. J., and Pyle, J. A.: Evaluation of the new UKCA climatecomposition model - Part 2: The Troposphere, Geosci. Model Dev., 7, 41-91, doi:10.5194/gmd-7-41-2014, 2014.

Park, S. and Bretherton, C. S.: The University of Washington Shallow Convection and Moist Turbulence Schemes and Their Impact on Climate Simulations with the Community Atmosphere Model, J. Climate, 22, 3449-3469, doi:10.1175/2008jcli2557.1, 2009.

Penner, J. E., Quaas, J., Storelvmo, T., Takemura, T., Boucher, O., Guo, H., Kirkevåg, A., Kristjánsson, J. E., and Seland, Ø.: Model intercomparison of indirect aerosol effects, Atmos. Chem. Phys., 6, 3391-3405, doi:10.5194/acp-6-3391-2006, 2006.

Penner, J. E., Xu, L., and Wang, M. H.: Satellite methods underestimate indirect climate forcing by aerosols, P. Natl. Acad. Sci. USA, 108, 13404-13408, doi:10.1073/pnas.1018526108, 2011.

Posselt, R. and Lohmann, U.: Sensitivity of the total anthropogenic aerosol effect to the treatment of rain in a global climate model, Geophys. Res. Lett., 36, L02805, doi:10.1029/2008g1035796, 2009.

Rosenfeld, D., Lohmann, U., Raga, G. B., O’Dowd, C. D., Kulmala, M., Fuzzi, S., Reissell, A., and Andreae, M. O.: Flood or drought: How do aerosols affect precipitation?, Science, 321, 1309-1313, doi:10.1126/science.1160606, 2008.

Quaas, J., Ming, Y., Menon, S., Takemura, T., Wang, M., Penner, J. E., Gettelman, A., Lohmann, U., Bellouin, N., Boucher, O., Sayer, A. M., Thomas, G. E., McComiskey, A., Feingold, G., Hoose, C., Kristjánsson, J. E., Liu, X., Balkanski, Y., Donner, L. J., Ginoux, P. A., Stier, P., Grandey, B., Feichter, J., Sednev, I., Bauer, S. E., Koch, D., Grainger, R. G., Kirkevåg, A., Iversen, T., Seland, Ø., Easter, R., Ghan, S. J., Rasch, P. J., Morrison, H., Lamarque, J.-F., Iacono, M. J., Kinne, S., and Schulz, M.: Aerosol indirect effects - general circulation model intercomparison and evaluation with satellite data, Atmos. Chem. Phys., 9, 8697-8717, doi:10.5194/acp-9-8697-2009, 2009.

Schmidt, G. A., Ruedy, R., Hansen, J. E., Aleinov, I., Bell, N., Bauer, M., Bauer, S., Cairns, B., Canuto, V., Cheng, Y., Del Genio, A., Faluvegi, G., Friend, A. D., Hall, T. M., Hu, Y. Y., Kelley, M., Kiang, N. Y., Koch, D., Lacis, A. A., Lerner, J., Lo, K. K., Miller, R. L., Nazarenko, L., Oinas, V., Perlwitz, J., Perlwitz, J., Rind, D., Romanou, A., Russell, G. L., Sato, M., Shindell, D. T., Stone, P. H., Sun, S., Tausnev, N., Thresher, D., and Yao, M. S.: Present-day atmospheric simulations using GISS ModelE: Comparison to in situ, satellite, and reanalysis data, J. Climate, 19, 153-192, doi:10.1175/jcli3612.1, 2006.

Schmidt, G. A., Kelley, M., Nazarenko, L., Ruedy, R., Russell, G. L., Aleinov, I., Bauer, M., Bauer, S. E., Bhat, M. K., Bleck, R., Canuto, V., Chen, Y. H., Cheng, Y., Clune, T. L., Del Genio, A., de Fainchtein, R., Faluvegi, G., Hansen, J. E., Healy, R. J., Kiang, N. Y., Koch, D., Lacis, A. A., LeGrande, A. N., Lerner, J., Lo, K. K., Matthews, E. E., Menon, S., Miller, R. L., Oinas, V., Oloso, A. O., Perlwitz, J. P., Puma, M. J., Putman, W. M., Rind, D., 
Romanou, A., Sato, M., Shindell, D. T., Sun, S., Syed, R. A., Tausnev, N., Tsigaridis, K., Unger, N., Voulgarakis, A., Yao, M. S., and Zhang, J. L.: Configuration and assessment of the GISS ModelE2 contributions to the CMIP5 archive, J. Adv. Model. Earth Syst., 6, 141-184, doi:10.1002/2013ms000265, 2014.

Small, J. D., Chuang, P. Y., Feingold, G., and Jiang, H. L.: Can aerosol decrease cloud lifetime?, Geophys. Res. Lett., 36, L16806, doi:10.1029/2009GL038888, 2009.

Song, X. L. and Zhang, G. J.: Microphysics parameterization for convective clouds in a global climate model: Description and single-column model tests, J. Geophys. Res.-Atmos., 116, D02201, doi:10.1029/2010jd014833, 2011.

Stevens, B. and Feingold, G.: Untangling aerosol effects on clouds and precipitation in a buffered system, Nature, 461, 607-613, doi:10.1038/nature08281, 2009.

Stevens, B., Giorgetta, M., Esch, M., Mauritsen, T., Crueger, T., Rast, S., Salzmann, M., Schmidt, H., Bader, J., Block, K., Brokopf, R., Fast, I., Kinne, S., Kornblueh, L., Lohmann, U., Pincus, R., Reichler, T., and Roeckner, E.: Atmospheric component of the MPI-M Earth System Model: ECHAM6, J. Adv. Model. Earth Syst., 5, 146-172, doi:10.1002/jame.20015, 2013.

Stier, P., Feichter, J., Kinne, S., Kloster, S., Vignati, E., Wilson, J., Ganzeveld, L., Tegen, I., Werner, M., Balkanski, Y., Schulz, M., Boucher, O., Minikin, A., and Petzold, A.: The aerosol-climate model ECHAM5-HAM, Atmos. Chem. Phys., 5, 1125-1156, doi:10.5194/acp-5-1125-2005, 2005.

Storelvmo, T., Kristjansson, J. E., and Lohmann, U.: Aerosol influence on mixed-phase clouds in CAM-Oslo, J. Atmos. Sci., 65, 3214-3230, doi:10.1175/2008jas2430.1, 2008.

Takemura, T., Nozawa, T., Emori, S., Nakajima, T. Y., and Nakajima, T.: Simulation of climate response to aerosol direct and indirect effects with aerosol transport-radiation model, J. Geophys. Res.-Atmos., 110, D02202, doi:10.1029/2004jd005029, 2005.

Takemura, T., Egashira, M., Matsuzawa, K., Ichijo, H., O’ishi, R., and Abe-Ouchi, A.: A simulation of the global distribution and radiative forcing of soil dust aerosols at the Last Glacial Maximum, Atmos. Chem. Phys., 9, 3061-3073, doi:10.5194/acp-93061-2009, 2009.

Tiedtke, M.: A comprehensive mass flux scheme for cumulus parameterization in large-scale models, Mon. Weather Rev., 117, 1779-1800, doi:10.1175/15200493(1989)117<1779:ACMFSF>2.0.CO;2, 1989.

Twomey, S.: Influence of pollution on shortwave albedo of clouds, J. Atmos. Sci., 34, 1149-1152, doi:10.1175/15200469(1977)034<1149:tiopot>2.0.co;2, 1977.

Walters, D. N., Williams, K. D., Boutle, I. A., Bushell, A. C., Edwards, J. M., Field, P. R., Lock, A. P., Morcrette, C. J., Stratton, R. A., Wilkinson, J. M., Willett, M. R., Bellouin, N., BodasSalcedo, A., Brooks, M. E., Copsey, D., Earnshaw, P. D., Hardiman, S. C., Harris, C. M., Levine, R. C., MacLachlan, C., Manners, J. C., Martin, G. M., Milton, S. F., Palmer, M. D., Roberts, M. J., Rodríguez, J. M., Tennant, W. J., and Vidale, P. L.: The Met Office Unified Model Global Atmosphere 4.0 and JULES Global Land 4.0 configurations, Geosci. Model Dev., 7, 361-386, doi:10.5194/gmd-7-361-2014, 2014.
Wang, H., Easter, R. C., Rasch, P. J., Wang, M., Liu, X., Ghan, S. J., Qian, Y., Yoon, J.-H., Ma, P.-L., and Vinoj, V.: Sensitivity of remote aerosol distributions to representation of cloud-aerosol interactions in a global climate model, Geosci. Model Dev., 6, 765-782, doi:10.5194/gmd-6-765-2013, 2013.

Wang, H. L. and Feingold, G.: Modeling Mesoscale Cellular Structures and Drizzle in Marine Stratocumulus. Part I: Impact of Drizzle on the Formation and Evolution of Open Cells, J. Atmos. Sci., 66, 3237-3256, doi:10.1175/2009jas3022.1, 2009a.

Wang, H. L. and Feingold, G.: Modeling Mesoscale Cellular Structures and Drizzle in Marine Stratocumulus. Part II: The Microphysics and Dynamics of the Boundary Region between Open and Closed Cells, J. Atmos. Sci., 66, 3257-3275, doi:10.1175/2009jas3120.1, 2009b.

Wang, M., Ghan, S., Ovchinnikov, M., Liu, X., Easter, R., Kassianov, E., Qian, Y., and Morrison, H.: Aerosol indirect effects in a multi-scale aerosol-climate model PNNL-MMF, Atmos. Chem. Phys., 11, 5431-5455, doi:10.5194/acp-11-5431-2011, 2011.

Wang, M., Liu, X., Zhang, K. and Comstock, J.: Aerosol indirect effects on cirrus throughice nucleation in CAM5 with a statistical cirrus cloud scheme, J. Adv. Model. Earth Syst. 6, 756-776, doi:10.1002/2014MS000339, 2014.

Wang, M. H., Ghan, S., Liu, X. H., L'Ecuyer, T. S., Zhang, K., Morrison, H., Ovchinnikov, M., Easter, R., Marchand, R., Chand, D., Qian, Y., and Penner, J. E.: Constraining cloud lifetime effects of aerosols using A-Train satellite observations, Geophys. Res. Lett., 39, L15709, doi:10.1029/2012g1052204, 2012.

Watanabe, M., Suzuki, T., O’Ishi, R., Komuro, Y., Watanabe, S., Emori, S., Takemura, T., Chikira, M., Ogura, T., Sekiguchi, M., Takata, K., Yamazaki, D., Yokohata, T., Nozawa, T., Hasumi, H., Tatebe, H., and Kimoto, M.: Improved Climate Simulation by MIROC5. Mean States, Variability, and Climate Sensitivity, J. Climate, 23, 6312-6335, doi:10.1175/2010jcli3679.1, 2010.

West, R. E. L., Stier, P., Jones, A., Johnson, C. E., Mann, G. W., Bellouin, N., Partridge, D. G., and Kipling, Z.: The importance of vertical velocity variability for estimates of the indirect aerosol effects, Atmos. Chem. Phys., 14, 6369-6393, doi:10.5194/acp14-6369-2014, 2014.

Wilson, D. R., Bushell, A. C., Kerr-Munslow, A. M., Price, J. D., and Morcrette, C. J.: PC2: A prognostic cloud fraction and condensation scheme. I: Scheme description, Q. J. Roy. Meteor. Soc., 134, 2093-2107, doi:10.1002/qj.333, 2008.

Zhang, K., O’Donnell, D., Kazil, J., Stier, P., Kinne, S., Lohmann, U., Ferrachat, S., Croft, B., Quaas, J., Wan, H., Rast, S., and Feichter, J.: The global aerosol-climate model ECHAM-HAM, version 2: sensitivity to improvements in process representations, Atmos. Chem. Phys., 12, 8911-8949, doi:10.5194/acp-12-89112012, 2012.

Zhang, K., Wan, H., Liu, X., Ghan, S. J., Kooperman, G. J., Ma, P.-L., Rasch, P. J., Neubauer, D., and Lohmann, U.: Technical Note: On the use of nudging for aerosol-climate model intercomparison studies, Atmos. Chem. Phys., 14, 8631-8645, doi:10.5194/acp-14-8631-2014, 2014. 